\title{
Rottlerin inhibits La Crosse virus-induced encephalitis in mice and blocks release of replicating virus from the Golgi body in neurons
}

\author{
Durbadal Ojha', Clayton W. Winkler', Jacqueline M. Leung ${ }^{1}$, Tyson A. Woods', Catherine Z. Chen $\left(\mathbb{1}^{2}\right.$, \\ Vinod Nair', Katherine Taylor', Charles D. Yeh ${ }^{1}{ }^{2}$, Gregory J. Tawa², Charles L. Larson', Wei Zheng $\mathbb{( D )}^{2}$, \\ Cathryn L. Haigh ${ }^{1}$ and Karin E. Peterson ${ }^{1 凶}$
}

La Crosse virus (LACV) is a mosquito-borne orthobunyavirus that causes approximately 60 to 80 hospitalized pediatric encephalitis cases in the United States yearly. The primary treatment for most viral encephalitis, including LACV, is palliative care, and specific antiviral therapeutics are needed. We screened the National Center for Advancing Translational Sciences library of 3,833 FDA-approved and bioactive small molecules for the ability to inhibit LACV-induced death in SH-SY5Y neuronal cells. The top three hits from the initial screen were validated by examining their ability to inhibit virus-induced cell death in multiple neuronal cell lines. Rottlerin consistently reduced LACV-induced death by $\mathbf{5 0 \%}$ in multiple human and mouse neuronal cell lines with an effective concentration of $0.16-0.69 \mathrm{\mu g} \mathrm{ml}^{-1}$ depending on cell line. Rottlerin was effective up to $12 \mathrm{hours}$ post-infection in vitro and inhibited virus particle trafficking from the Golgi apparatus to trans-Golgi vesicles. In human inducible pluripotent stem cell-derived cerebral organoids, rottlerin reduced virus production by one log and cell death by $35 \%$ compared with dimethyl sulfoxide-treated controls. Administration of rottlerin in mice by intraperitoneal or intracranial routes starting at 3 days post-infection decreased disease development by 30-50\%. Furthermore, rottlerin also inhibited virus replication of other pathogenic California serogroup orthobunyaviruses (Jamestown Canyon and Tahyna virus) in neuronal cell lines.

a Crosse virus (LACV), a California serogroup (CSG) mosquito-borne arbovirus endemic to North America, can induce a rare, life-threatening neurological disease in children $^{1,2}$. First isolated in Wisconsin, USA, in the early $1960 \mathrm{~s}^{3,4}$, LACV encephalitis (LACV-E) cases have been found in more than 20 states $^{5}$. The life cycle of LACV is maintained between the vector, the eastern tree-hole mosquito Aedes triseriatus and vertebrate hosts including eastern grey squirrels and chipmunks ${ }^{6,7}$.

Humans are 'dead-end' hosts as LACV does not reach sufficient viremia levels to be picked up by mosquitos ${ }^{8}$. Most LACV infections in humans are asymptomatic or induce mild clinical symptoms of fever, headache, lethargy and vomiting ${ }^{9}$. However, in some cases LACV causes severe neuroinvasive disease requiring hospitalization $^{2}$. Most LACV-E cases occur in children under 16 years of age ${ }^{10}$. To date, there is neither a licensed vaccine ${ }^{11}$ nor an antiviral therapy approved by the Food and Drug Administration (FDA) to prevent or treat LACV-E'.

Mouse models, neuronal cell lines (NCLs) and human cerebral organoids (hCOs) have provided insights into the mechanisms of LACV-induced neuronal damage. Mice demonstrate an age-related resistance to LACV-induced neurological disease (LACV-ND), with mice 3 weeks old or younger being highly susceptible to disease development. Virus is detected in the brain by 3 days post-infection (dpi), and pathogenesis appears to be primarily driven by virus infection and apoptosis of neurons ${ }^{12-15}$.

Human neuronal cells also undergo apoptosis following LACV infection as observed in human NCLs ${ }^{16}$, neuron-astrocyte co-cultures ${ }^{17}$ and cerebral organoids ${ }^{18}$. In recent studies with hCOs, LACV induced changes in the structural density of hCOs starting at $3 \mathrm{dpi}$. These hCOs contain neurons at different stages of differentiation, but not microglia, astrocytes or oligodendrocytes. Thus, they are useful models to study infection of human neurons in a complex, structured environment ${ }^{18}$ and provide a system with heterogeneous human neural-lineage cell types to analyse therapeutics and other reagents to prevent LACV-induced neuronal death.

Therapeutics for LACV-E need to be effective when administered after viral encephalitis has been diagnosed. At this time, LACV has entered the central nervous system (CNS), infecting and inducing apoptosis of neurons. Thus, an effective drug needs to inhibit virus replication in neurons or virus-induced neuronal cell death. LACV enters cells through clathrin-mediated endocytosis ${ }^{19}$ and traffics to early endosomes, where uncoating of the viral genome occurs followed by viral RNA transcription in the cytoplasm ${ }^{19,20}$. Viral proteins are transported to the Golgi for viral assembly and mature viruses are trafficked by Golgi-derived vesicles to the plasma membrane for release $^{20}$. Compounds that inhibit virus entry, uncoating, transcription, translation, assembly or trafficking without causing neuronal damage would be ideal therapeutics for LACV-E.

In this study, we conducted a high-throughput screen of approved drugs and bioactive small molecules to identify compounds that inhibit LACV-induced neuronal death. We identified 10 potential compounds and further analysed the three most promising candidates. One compound, rottlerin (RTL), showed strong therapeutic potential in vitro, in hCOs and in a mouse model.

\section{Results}

Screen of compounds for inhibition of LACV-induced cell death. A total of 3,833 compounds from the library of the National Center 


\begin{tabular}{|c|c|c|c|c|}
\hline Cell line used & NBI 27914 & RTL & Tyrphostin AG879 & T-705 (favipiravir) \\
\hline $\mathrm{CC}_{50}\left(\mu \mathrm{g} \mathrm{ml^{-1 }}\right)$ & $51.2 \pm 5.4$ & $5.8 \pm 1.4$ & $\geq 100$ & $524.9 \pm 6.8$ \\
\hline $\mathrm{EC}_{50}\left(\mu \mathrm{g} \mathrm{ml}^{-1}\right)$ & 35.9 & $0.69 \pm 0.02$ & - & $7.6 \pm 0.5$ \\
\hline $\mathrm{CC}_{50}\left(\mu \mathrm{g} \mathrm{ml}^{-1}\right)$ & $27.6 \pm 3.6$ & $6.8 \pm 1.2$ & $\geq 100$ & $204.2 \pm 9.8$ \\
\hline $\mathrm{EC}_{50}\left(\mu \mathrm{g} \mathrm{ml}^{-1}\right)$ & - & $0.18 \pm 0.07$ & 34.8 & $101.4 \pm 4.4$ \\
\hline $\mathrm{SI}$ & - & 37.78 & $\geq 2.87$ & 2.01 \\
\hline \multicolumn{5}{|l|}{$\mathrm{C} 17.2$} \\
\hline \multicolumn{5}{|l|}{ SH-SY5Y } \\
\hline $\mathrm{CC}_{50}\left(\mu \mathrm{g} \mathrm{ml}^{-1}\right)$ & $53.2 \pm 6.3$ & $1.8 \pm 0.3$ & $31.5 \pm 2.8$ & 252.6 \\
\hline $\mathrm{EC}_{50}\left(\mu \mathrm{g} \mathrm{ml}^{-1}\right)$ & 31.3 & $0.16 \pm 0.02$ & $23.7 \pm 1.4$ & - \\
\hline SI & 1.7 & 11.25 & 1.33 & - \\
\hline \multicolumn{5}{|l|}{ hNSCs } \\
\hline $\mathrm{CC}_{50}\left(\mu \mathrm{gml}^{-1}\right)$ & ND & $3.8 \pm 0.5$ & ND & $166.5 \pm 8.2$ \\
\hline $\mathrm{EC}_{50}\left(\mu \mathrm{g} \mathrm{ml}^{-1}\right)$ & ND & $0.3 \pm 0.03$ & ND & - \\
\hline SI & ND & 12.67 & ND & - \\
\hline \multicolumn{5}{|l|}{ Primary neurons } \\
\hline $\mathrm{CC}_{50}\left(\mu \mathrm{g} \mathrm{ml}^{-1}\right)$ & ND & $1.6 \pm 0.8$ & ND & ND \\
\hline
\end{tabular}

Mean \pm s.d., determined from three independent experiments; ND, not determined; ' ${ }^{\prime}$, not calculated due to inability to inhibit cell death by $50 \%$. $\mathrm{CC}_{50}$, the cytotoxic concentration ( $\mu \mathrm{g} \mathrm{ml}^{-1}$ ) of the drugs causing death of $50 \%$ of viable cells. $\mathrm{EC}_{50}$, concentration $\left(\mu \mathrm{g} \mathrm{ml}{ }^{-1}\right)$ producing $50 \%$ inhibition of virus-induced cell deaths. Sl, selectivity index, the ratio between $\mathrm{CC}_{50}$ and $\mathrm{EC}_{50}$.

for Advancing Translational Sciences (NCATS) Pharmaceutical Collection of FDA-approved drugs and the library of pharmacologically active compounds (LOPAC1280) were screened using the human SH-SY5Y NCL infected with LACV at 0.01 multiplicity of infection (MOI) (Extended Data Fig. 1a). Cell viability was measured using a high-throughput ATP-content assay to identify compounds that inhibited LACV-mediated cell death. These screening data are available as PubChem bioassay assay ID 1508616. A total of 4,096 compounds were tested, with 263 duplicate compounds and 3,830 compounds listed in the PubChem library. Of these, 32 compounds showed $>80 \%$ protection. Ten of these 32 compounds were positive in a confirmation run of the same assay (Extended Data Fig. 1b-k). The top three hits (NBI 27914, RTL and tyrphostin AG879) were selected for further analysis.

Analysis of selected compounds in multiple cell lines. Toxicity analysis of the top three compounds was completed in Vero cells, two rodent-derived NCLs (N2a, C17.2) and SH-SY5Y cells. For each compound and cell line, a dose-response curve without virus infection was plotted to determine the $50 \%$ cellular toxicity $\left(\mathrm{CC}_{50}\right)$ as summarized in Table 1 . A similar assay, with the addition of LACV infection, was used to determine the $50 \%$ effective concentration $\left(\mathrm{EC}_{50}\right)$, the concentration of the drug that inhibited LACV-induced cell death by $50 \%$ (Table 1 and Extended Data Fig. 2a). The ratio of $\mathrm{CC}_{50}$ to $\mathrm{EC}_{50}$ provided the selectivity index (SI), the difference in the drug concentration that is toxic to cells versus the concentration that inhibits virus-induced cell death ${ }^{21}$. Of the three drugs examined, only RTL had a high SI for all cell lines (Table 1). The other two drugs, NBI 27914 and tyrphostin AG879, were inconsistent in inhibiting virus-induced death between the cell lines (Table 1). T-705 was also tested as a positive control ${ }^{22}$ and showed a high SI in Vero cells but not in neuronal cells (Table 1 and Extended Data Fig. 2b). RTL was then further tested in human neural stem cells (hNSCs) and mouse primary neurons, with an SI of 12.67 and 5 in these cells, respectively (Table 1 and Extended Data Fig. 2a). Thus, RTL inhibited LACV-induced cell death in all cell lines tested, indicating a consistent antiviral drug against LACV.

Effect of RTL on virus replication. We next examined whether RTL inhibited LACV infection, replication or release by measuring virus titres from cell supernatants. Treatment with RTL at doses of $\mathrm{EC}_{50}$ and $2 \times \mathrm{EC}_{50}$ significantly reduced virus levels in cell supernatants by up to three logs in all neuronal cell cultures (Fig. 1a-d). Quantitative real-time (qRT)-PCR analysis of RNA levels of the viral S gene segment (Extended Data Fig. $2 \mathrm{c}-\mathrm{f}$ ) as well as the $\mathrm{M}$ and L segments (Supplementary Fig. 1) showed that RTL decreased viral RNA production by up to two logs. Immunofluorescence analysis of infected N2a or SH-SY5Y cell monolayers at 24 hours post-infection (hpi) showed that RTL significantly reduced the number of infected cells compared with dimethyl sulfoxide (DMSO)-treated cells (Fig. 1e-h). Thus, RTL treatment significantly lowered the percentage of infected cells, which was associated with reduced viral RNA and infectious virus particles. 
Analysis of RTL activity at early time points in virus replication. As RTL had similar effects on all cell lines, we focused on SH-SY5Y and hNSCs to study the mechanism by which RTL inhibits LACV replication. To determine whether RTL inhibited LACV before or after viral entry, cells were treated with RTL before infection (pre-treatment), during infection (co-treatment), after infection (post-treatment) or by continuous treatment (CT) at all three time points. Neither pre- nor co-treatment of SH-SY5Y cells or hNSCs with RTL inhibited LACV-induced neuronal death (Fig. 1i). RTL did not affect virus attachment (Extended Data Fig. 3a,b) and pre-incubation of RTL with virus did not affect LACV replication (Extended Data Fig. 2c), indicating that RTL did not inhibit virus entry. However, RTL inhibited cell death when added post-infection (PI) or maintained continuously (Fig. 1i). Thus, RTL reduced LACV-induced cell death when added after the initial stage of infection in SH-SY5Y cells and hNSCs.

Kinetic determination of RTL inhibition. To determine how late PI RTL could be added to inhibit LACV, we added RTL at different time intervals. Inhibition of cell death (Fig. 1j), virus production in the supernatant (Extended Data Fig. 3d) and viral RNA levels within the cells (Fig. 1k and Extended Data Fig. 3e,f) was observed at all time points, with a slight drop-off from 8-12 hpi. Similar results were observed with different MOIs of virus (Extended Data Fig. 3g,h). Thus, RTL was effective when added PI, with no observable difference when treatment was delayed to up to 8 hpi. This time point also correlated with the normal production of large amounts of virus from neuronal cells (Extended Data Fig. 3i). Together, these data suggest that RTL may inhibit a later stage of LACV replication in the cell, possibly virus assembly or release. Due to the similar effects of RTL on SH-SY5Y cells and hNSCs, further studies were done with hNSCs alone, as hNSCs are not an immortalized cell line and were more amenable to immunohistochemistry (IHC) and transmission electron microscopy (TEM) analysis.

Analysis of RTL effect on LACV localization within the cell. Orthobunyavirus replication includes virus assembly inside the Golgi complex and release with the help of Golgi vesicles ${ }^{20}$. To determine whether RTL affected LACV replication in the Golgi, we compared RTL to the Golgi inhibitor brefeldin A (BFA). BFA did not have any synergistic effect with RTL on inhibiting LACV replication, suggesting that RTL acts at a similar or later stage of virus replication (Extended Data Fig. 4a). Analysis of virus replication in hNSCs showed that association of LACV proteins with giantin (medial Golgi)-positive membranes was minimal at $6 \mathrm{hpi}$, but pronounced at 8-12 hpi, with large clusters of virus particles appearing to leave the Golgi at this time (Extended Data Fig. 4b-e). We next analysed LACV-infected hNSCs that were treated with RTL at $8 \mathrm{hpi}$ by IHC at 24 hpi. Cells were labelled with cis-Golgi (Fig. 2a), medial Golgi (Fig. 2b) or trans-Golgi (Fig. 2c) markers and anti-LACV antibody. LACV proteins were more closely associated with markers for the cis-, medial and trans-Golgi compartments in cells treated with RTL compared with the DMSO-treated cells (Fig. 2a-c, Extended Data Fig. 4 f and Supplementary Videos 1, 2). The majority of LACV signal (79\%) was retained within the medial Golgi in RTL-treated cells, compared with $38 \%$ in DMSO-treated controls (Fig. 2d). No gross differences in morphology were observed in the medial Golgi of uninfected RTL-treated cells compared with DMSO-treated controls (Fig. 2e,f), suggesting that the effect of RTL on LACV localization was not due to a change in Golgi architecture.

As viral protein translation initiates in the endoplasmic reticulum $(\mathrm{ER})^{20}$ and RTL has been reported to modulate the morphological integrity of the ER-Golgi intermediate compartment (ERGIC) $)^{23}$, we also analysed these organelles. However, no visible differences in LACV localization were observed for either the ER or ERGIC in RTL-treated versus control cells (Extended Data Fig. 4g,h). Thus, RTL treatment resulted in the accumulation of LACV signal inside the Golgi, suggesting that virus release from the Golgi was impaired.

To examine virus particles inside the cell more closely, we utilized TEM. LACV-infected hNSCs were treated with RTL or DMSO at $8 \mathrm{hpi}$ and then examined at $24 \mathrm{hpi}$. Uninfected RTL-treated cells (Fig. 3b) showed no difference from untreated uninfected cells in Golgi structure (Fig. 3a). In control DMSO-treated LACV-infected hNSCs, virus was primarily observed extracellularly, but was also found inside the cell (Fig. 3c,d). Intracellular virus particles in both DMSO- and RTL-treated hNSCs were found in vesicles (Fig. 3d-f). However, in RTL-treated cells, these virus-enclosing vesicles were generally larger and often contained multiple virus particles (Fig. 3e,f). Thus, LACV-infected cells treated with RTL had virus particles in vesicles near the Golgi that appeared aberrant compared with DMSO-treated cells.

Effect of RTL on LACV infection of hCOs. We next examined whether RTL could inhibit neuronal death in a more complex system, inducible pluripotent human stem cell-derived COs. In our previous studies, LACV infection of 3-week-old hCOs resulted in neuronal apoptosis and decreased organoid viability ${ }^{18}$.

Fig. 1 | Anti-LACV activity of RTL in multiple NCLs. a-d, Viral titre in cell supernatant from N2a cells (a), primary neurons (b), SH-SY5Y cells (c) and hNSCs (d) following LACV infection and treatment with RTL at EC 50 and $2 \times E_{50}$ or vehicle control (VC) after 1 hpi. At specific time intervals (12, 24 and $48 \mathrm{hpi}$ ), cell supernatant was collected for plaque assay. Each line graph represents the mean \pm s.d. of nine individual wells per cell type combined from three independent experiments, except for primary neurons where error bars represent differences among three individual wells of a single experiment. ${ }^{\star} P<0.05,{ }^{\star \star \star} P<0.001$ and ${ }^{\star \star \star \star} P<0.0001$; statistics were determined with one-way analysis of variance (ANOVA) at each time point using Dunnett's multiple-comparisons test. e-h, Immunofluorescence labelling of LACV (magenta) and host cell nuclei (cyan) of N2a (e) and SH-SY5Y (g) cells, uninfected (cell control, CC) or infected with LACV and treated with $E_{50}$ and $2 \times E C_{50}$ RTL. $-L A C V$, $-R T L$ indicates uninfected and untreated control; +LACV, -RTL (DMSO) indicates infection control treated with DMSO; +LACV, +RTL indicates infected and treated with RTL. Scale bars, $50 \mu \mathrm{m}$. Images are representative of three replicate experiments. The percentages of LACV-infected N2a cells are shown in $\mathbf{f}$ and those for SH-SY5Y cells are shown in $\mathbf{h}$. For N2a cells, we analysed a total of 870 cells for vehicle control, 1,444 cells for $E_{50}$ and 1,473 cells for $2 \times E_{50}$ from three independent replicate experiments. For SH-SY5Y cells, we analysed 1,917 cells for VC, 2,189 cells for $\mathrm{EC}_{50}$ and 2,781 cells for $2 \times \mathrm{EC}_{50}$ from three independent replicate experiments. Each symbol represents a single data point corresponding to one field of the viewed image. ${ }^{\star \star \star \star} P<0.0001$; one-way ANOVA. i-k, Effect of time of RTL $\left(2 \times E_{50}\right.$ dose) addition on LACV-infected SH-SY5Y cells and hNSCs. Circles represent SH-SY5Y cells and squares represent hNSCs. In i, SH-SY5Y cells and hNSCs were treated with RTL ( $2 \times \mathrm{EC}_{50}$ dose) as pre-treatment (cells were treated with RTL before infection for $\left.3 \mathrm{~h}\right)$, co-treatment ( $R T L$ and virus were added together for $2 \mathrm{~h}$ ), post-treatment (RTL was added at $2 \mathrm{hpi}$ and maintained for the rest of the experiment) and continuous treatment (CT; all three time points together) with respect to LACV infection ( $0.1 \mathrm{MOI})$. Cell survival was measured at $48 \mathrm{hpi}$ by MTT assay. Effects of time of RTL addition PI on cell survival by MTT assay $(2,4,6,8$ and $12 \mathrm{~h})$ and on viral RNA expression $(2,4,8$ and $12 \mathrm{~h})$ are shown in $\mathbf{j}$ and $\mathbf{k}$, respectively. MTT was carried out at $48 \mathrm{hpi}$, while RNA was isolated at $24 \mathrm{hpi}$ followed by qRT-PCR analysis. Viral RNA expression for each sample was calculated as the percentage of viral mRNA expression relative to GAPDH mRNA in the sample as described in the Methods. Data shown in i-k are for nine individual wells per group combined from three independent experiments. ${ }^{\star \star \star \star} P<0.0001$; one-way ANOVA using Dunnett's multiple-comparisons test. 
hCOs infected with LACV were treated at $24 \mathrm{hpi}$ with $0.3 \mu \mathrm{g} \mathrm{ml}^{-1}$ RTL and followed for viability and virus production. RTL-treated hCOs had increased cell survival (Fig. 4a) and reduced virus production (Fig. 4b) compared with DMSO-treated controls. IHC staining for viral antigen correlated with these results (Extended Data Fig. 5a,b), although the varied structure, size and areas of virus infection did not allow for clear quantification of infection or apoptosis. Analysis of older 11-week-old hCOs showed some dose-dependent low-level toxicity of RTL (Extended Data Fig. 5c) of up to $12 \%$ with $0.3 \mu \mathrm{g} \mathrm{ml}^{-1} \mathrm{RTL}$ and up to $20 \%$ with $1 \mu \mathrm{g} \mathrm{ml}^{-1} \mathrm{RTL}$. However, even with the added toxicity, RTL treatment still significantly increased cell survival following LACV infection (Fig. 4c) and reduced virus production (Fig. 4d) in the 11-week-old hCOs in a dose-dependent manner. Thus, RTL inhibited LACV-induced cell loss in the complex structure of 3- and 11-week-old hCOs.
Effect of RTL on LACV-ND in mice. To examine whether RTL could inhibit LACV pathogenesis in vivo, we utilized a mouse model of LACV-ND ${ }^{12}$. RTL toxicity was assessed by intraperitoneal (IP) administration at $20 \mathrm{mg}$ per kg body weight daily in 24-day-old Macrophage Fas-Induced Apoptosis (MAFIA) mice for $7 \mathrm{~d}$ or by intracranial (IC) inoculation at $1 \mathrm{mg}$ perkg body weight in 25 - and 29-day-old MAFIA mice. MAFIA mice express green fluorescent protein (GFP) under the control of the Csf1r promoter, allowing for easy analysis of myeloid cell activation, but are otherwise fully immunocompetent. Most animals showed no response to RTL administration; however, a few mice treated by IC inoculation had short-term inactivity. Therefore, the IC dose was reduced fourfold to $250 \mu$ g perkg body weight for therapeutic studies. No negative effect was observed with IP inoculations, consistent with previous studies ${ }^{24}$. Histopathological analysis of kidney, liver and

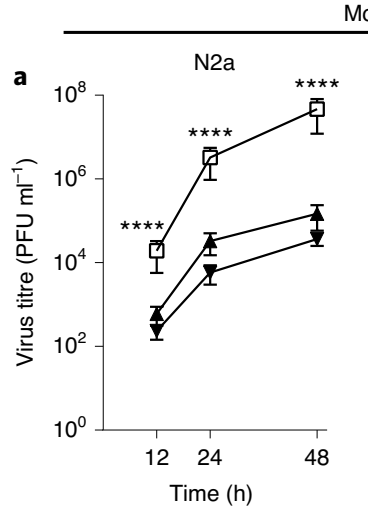

曰 VC (DMSO)
Mouse

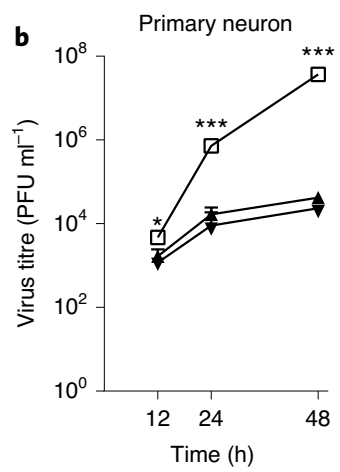

\ $\operatorname{RTL}\left(\mathrm{EC}_{50}\right) \quad$ V RTL $\left(2 \times \mathrm{EC}_{50}\right)$

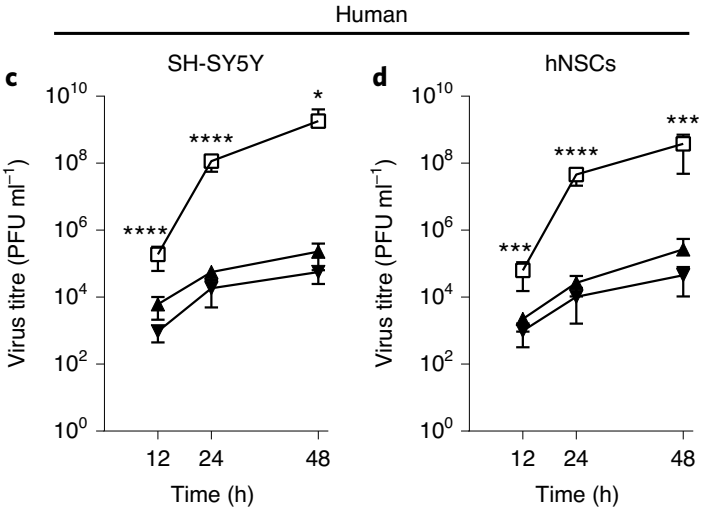

e

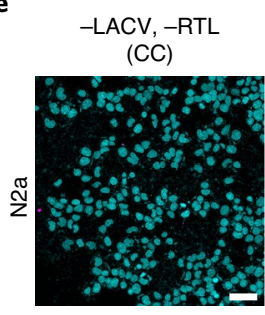

$+\mathrm{LACV},-\mathrm{RTL}$ (DMSO)

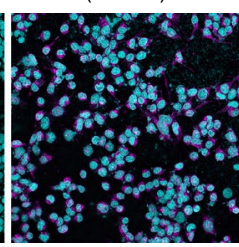

g

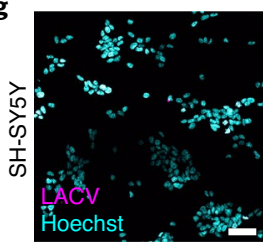

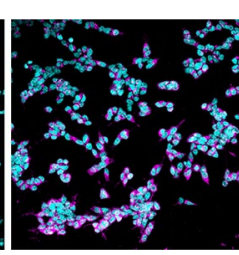

$+\mathrm{LACV},+\mathrm{RTL}$

$\left(\mathrm{EC}_{50}\right)$
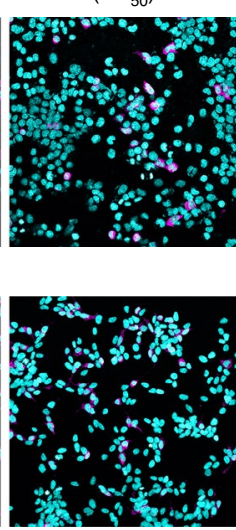

$+\mathrm{LACV},+\mathrm{RTL}$

$\left(2 \times \mathrm{EC}_{50}\right)$
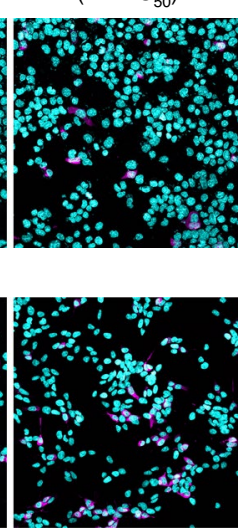
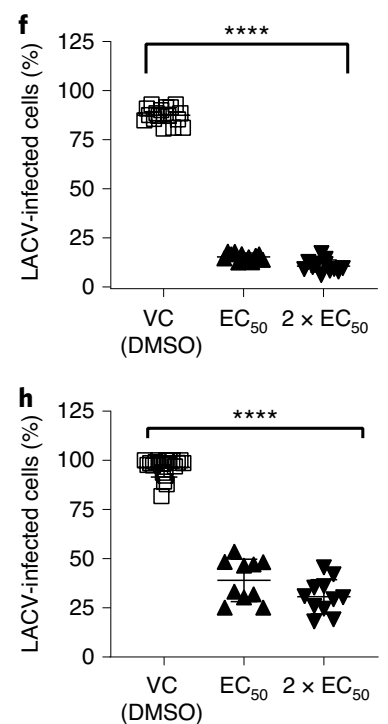

i

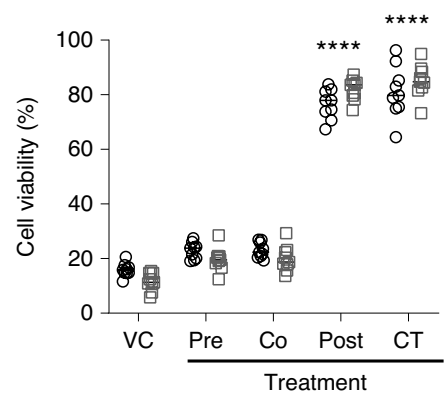

j

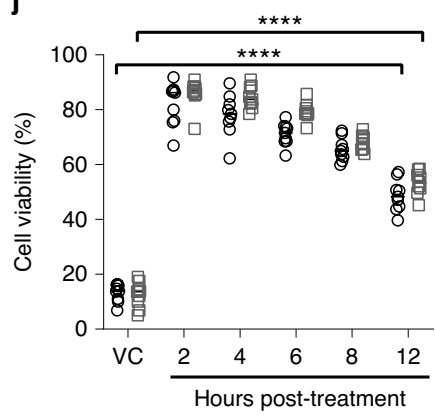

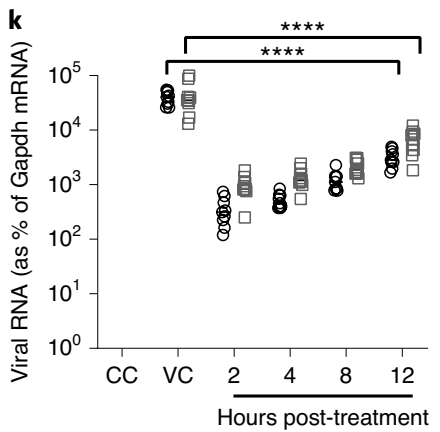



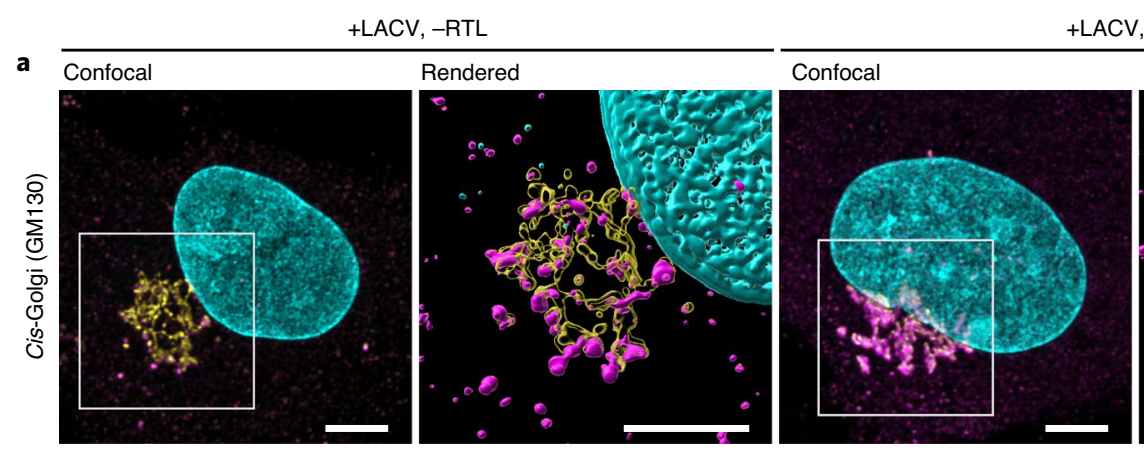

$+\mathrm{LACV},+\mathrm{RTL}$
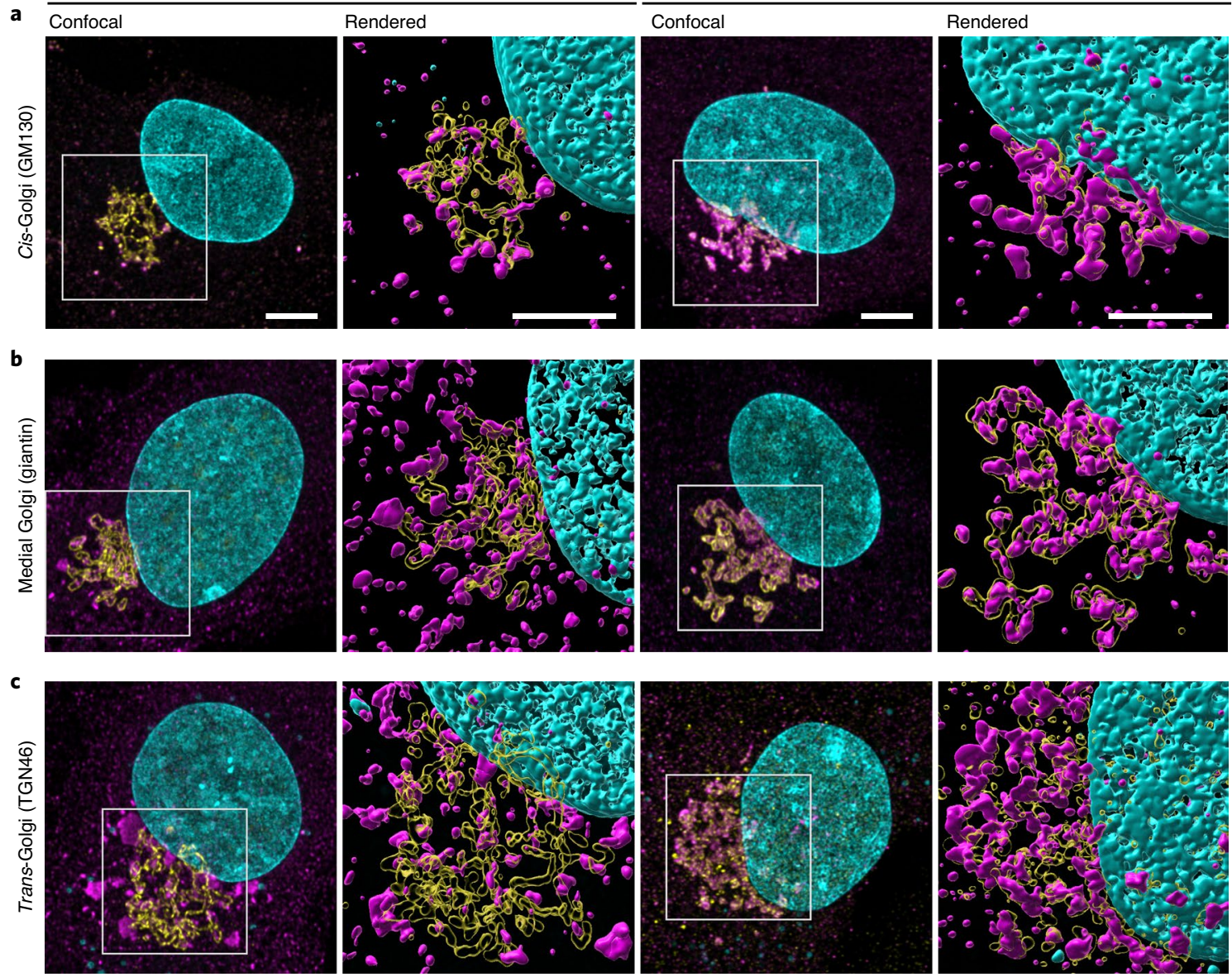

d
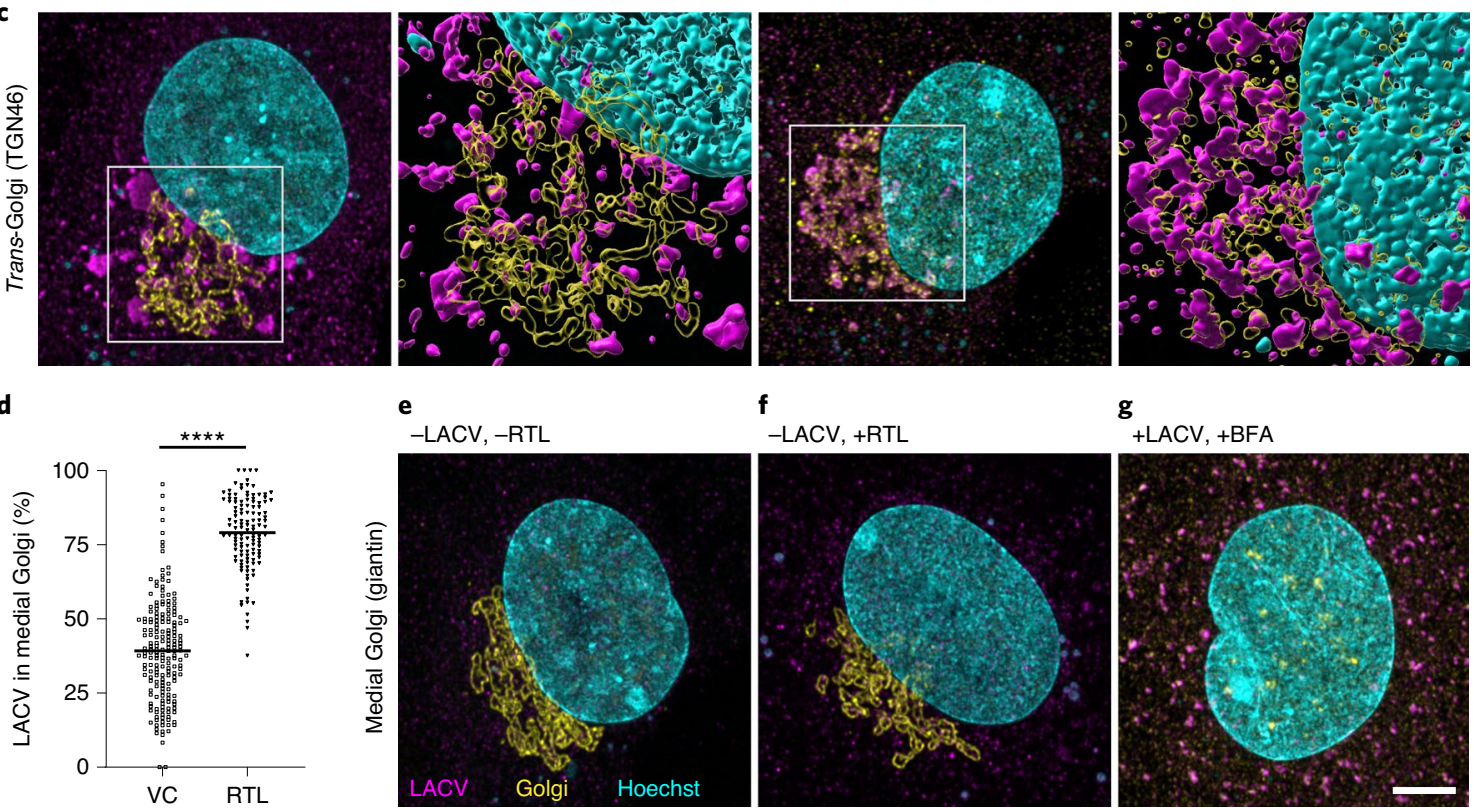

g + LACV, + BFA

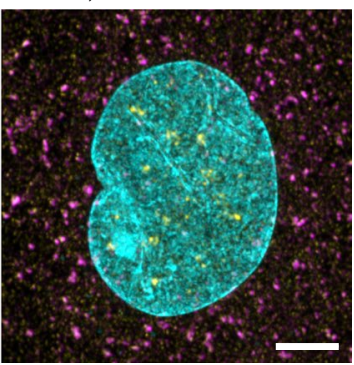

Fig. 2 | LACV localization in Golgi after RTL treatment of LACV-infected hNSCs. a-c, LACV-infected hNSCs were treated with DMSO or RTL at a dose of $2 \times \mathrm{EC}_{50}$ at $8 \mathrm{hpi}$. At $24 \mathrm{hpi}$, cells were immunostained with antibodies against LACV (magenta) and the cis- (GM130) (a), medial (giantin) (b) and trans- (TGN46) (c) Golgi (yellow for all) and imaged using a confocal microscope. Confocal images were deconvolved and maximum-intensity projections are shown. Rendered images are shown after segmentation and surface rendering in Imaris. Imaris 3D-rendered insets are at twice the magnification of the confocal images. Images are representative of two to three replicate experiments. $\mathbf{d}$, Percentage of integrated LACV signal intensity in the medial Golgi signal. We analysed 397 cells for vehicle control and 316 cells for RTL treatment at 8 hpi from three independent biological replicates. Individual cells are shown as replicates with a line indicating the mean. ${ }^{\star \star \star \star} P<0.0001$; unpaired two-tailed Welch's $t$-test. e, Uninfected, DMSO-treated control. f, Uninfected, RTL-treated control. g, LACV-infected, BFA-treated control. +LACV, $-\mathrm{RTL}$ indicates infection control treated with DMSO; +LACV, +RTL indicates infected and treated with RTL; - LACV, $-R T L$ indicates uninfected and untreated control; $-L A C V,+R T L$ indicates uninfected and RTL-treated control; $+\mathrm{LACV},+\mathrm{BFA}$ indicates infected and treated with BFA. Scale bars (for all confocal images), $5 \mu \mathrm{m}$. Images are representative of two to three replicate experiments.

spleen in RTL-treated animals showed normal histology and no increased GFP expression in brain tissue compared with controls (Supplementary Fig. 2). Thus, RTL did not appear to have toxic effects in young mice.

In most instances of LACV-E, the disease is not detected or diagnosed until neurological signs occur, indicating virus in the CNS.
Therefore, we started treatment at $3 \mathrm{dpi}$, a time when LACV is consistently found in infected neurons of the brain ${ }^{14}$. LACV-infected mice were administered either $20 \mathrm{mg}$ per kg RTL per day by IP inoculation at 3-10 dpi or $250 \mu$ per kg RTL by IC inoculation at 4 and 7 dpi. LACV-infected mice treated with vehicle control (DMSO) by either the IP or IC route had a clinical disease rate of $78-81 \%$ 

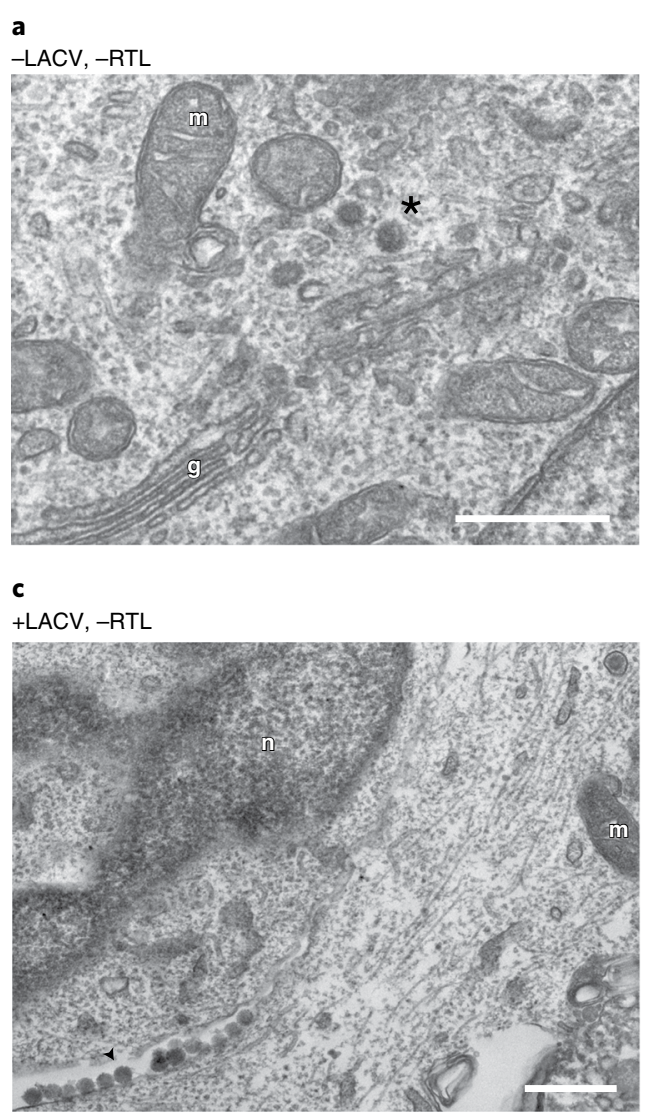

e

$+\mathrm{LACV},+\mathrm{RTL}$

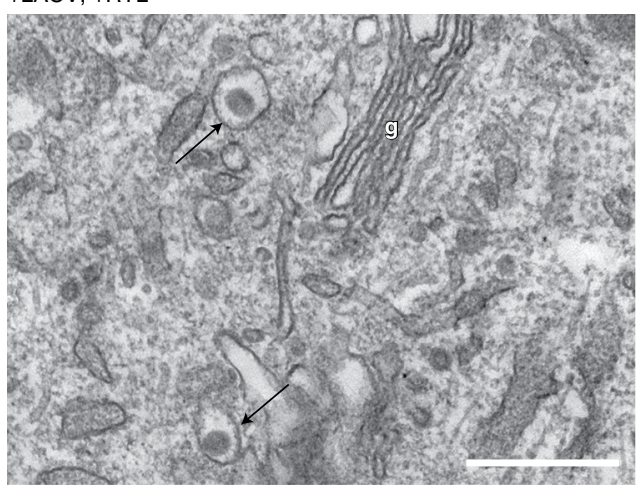

b

$-\mathrm{LACV},+\mathrm{RTL}$

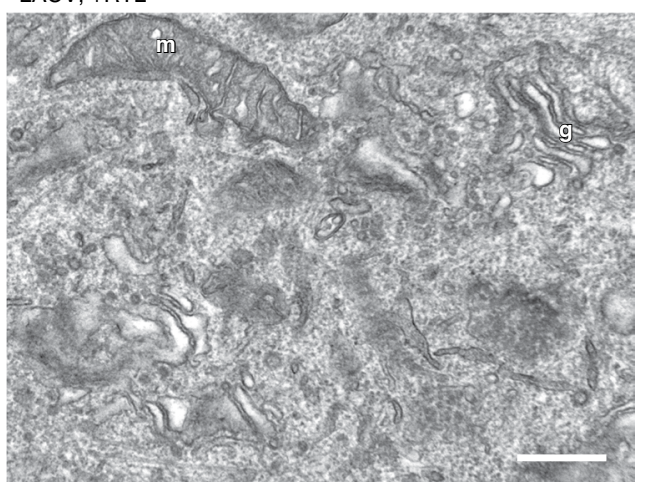

d

$+\mathrm{LACV},-\mathrm{RTL}$

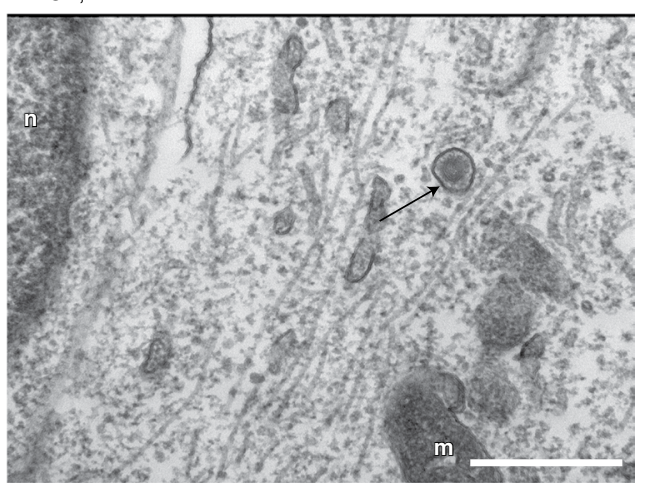

f

$+\mathrm{LACV},+\mathrm{RTL}$

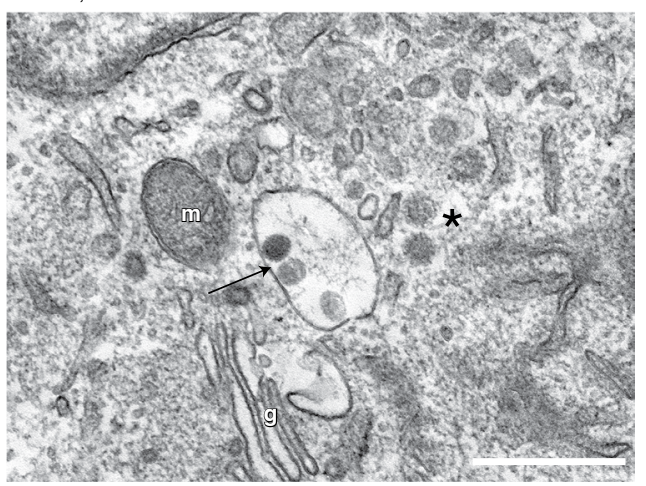

Fig. 3 | TEM images of RTL ( $2 \times$ EC $_{50}$ dose)-treated LACV-infected hNSCs. a-f, hNSCs were either left uninfected (a,b) or infected (c-f) with LACV $(0.1 \mathrm{MOI})$ for $1 \mathrm{~h}$ and then left untreated $(\mathbf{a})$ or treated with DMSO $(\mathbf{c}, \mathbf{d})$ or RTL $(\mathbf{b}, \mathbf{e}, \mathbf{f})$ starting at 8 hpi until cells were fixed at 24 hpi. DMSO-treated LACV-infected hNSCs showed both extracellular viruses (c) (arrowhead) and intracellular virus in vesicles (d) (arrow). In e,f, LACV-infected hNSCs treated with RTL had virus contained mostly inside vesicles (arrows) that were adjacent to Golgi stacks. Similar findings were observed in two replicate TEM experiments, with consistent findings in each group. Scale bars, $500 \mathrm{~nm}$. An asterisk indicates a cellular organelle with similar size as virus in the cytoplasm of the uninfected untreated control (a) and infected RTL-treated (f) groups. In contrast, the virus-containing vesicles observed in c-f were not seen in uninfected controls. g, Golgi; m, mitochondria; $n$, nucleus.

(Fig. 5a,b). Incidence of disease in DMSO-treated mice was slightly less than in untreated animals, suggesting that DMSO alone may also have a slight protective effect. RTL treatment via either the IP or IC route significantly decreased the incidence of neurological disease compared with DMSO-treated mice (Fig. 5a,b). Thus, RTL treatment inhibited LACV pathogenesis in vivo.

We also studied whether RTL protected against LACV-ND when administered through the oral route. Unfortunately, oral administration of RTL was not as effective as IP or IC inoculation, with no statistical difference in disease relative to controls (Extended Data Fig. 6a). Analysis of T-705 in vivo showed a slight, but not significant, decrease in neurological disease. Thus, RTL but not T-705 treatment was effective in inhibiting LACV-ND in mice (Extended Data Fig. 6b). RTL was most effective when administered by the IC or IP route, but not when administered orally.

Analysis of viral RNA (Fig. 5c,d) and replicating virus (Fig. 5e,f) showed a slight but not significant decrease in virus levels in RTL-treated mice at $5 \mathrm{dpi}, 1-2 \mathrm{~d}$ after RTL treatment was initiated. However, by $8 \mathrm{dpi}$, a significant decrease was observed in RTL-treated mice, with non-clinical mice having reduced viral RNA and replicating virus in the brain (Fig. 5c-f). IHC analysis of non-clinical mice at $8 \mathrm{dpi}$ showed widespread viral infection 

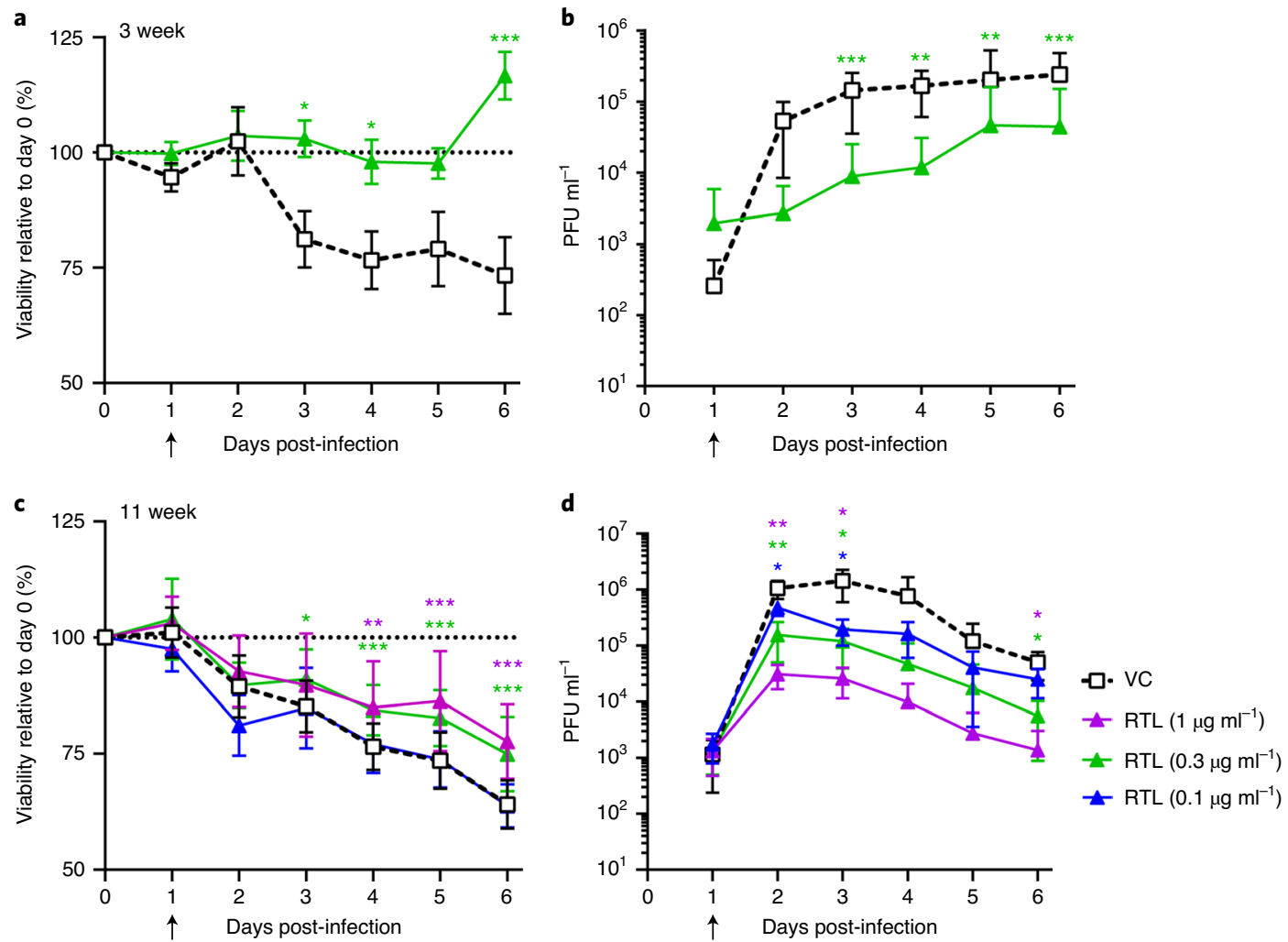

Fig. 4 | RTL treatment inhibits LACV infection in hCOs. a-d, hCOs (3 weeks old $(\mathbf{a}, \mathbf{b})$ and 11 weeks old (c, d)) were infected with $1 \times 10^{3}$ PFU of LACV. At $1 \mathrm{dpi}$ (arrows), hCOs were treated with RTL or DMSO and followed to $6 \mathrm{dpi}$. In a,c, hCOs were assayed daily for cell viability using a resazurin reduction-based colorimetric assay dye. Dye fluorescence for each organoid on every day was compared to the fluorescence of the same organoid on day 0 to provide a percentage of viability compared to baseline. This was done to control for organoid size. Each symbol represents the mean $\pm \mathrm{s}$.d. of $6 \mathrm{hCO}$ in each group for both 3-week-old and 11-week-old COs. ${ }^{\star} P<0.05$, ${ }^{\star \star} P<0.01$ and ${ }^{\star \star \star} P<0.001$; two-way ANOVA with Dunnett's multiple-comparisons test. b,d, Viral titre in the supernatant at 24-h time intervals for 3-week-old (b) and 11-week-old (d) hCOs following LACV infection (day 0) and RTL treatment (arrows). For 3-week-old hCOs, each symbol represents the mean \pm s.d. of three independent experiments on 17 organoids for up to 3 dpi and 12 organoids for 4 to $6 \mathrm{dpi}$. For 11 -week-old hCOs, one experiment with six organoids per group per time point was performed. ${ }^{\star} P<0.05$, ${ }^{\star \star} P<0.01$ and ${ }^{* \star} P<0.001$; two-way ANOVA with Sidaks's multiple-comparisons test.

throughout the brain in DMSO-treated mice (Fig. 5g-i) compared with mock-infected controls (Extended Data Fig. 6c,d). In contrast, RTL-treated mice appeared to have more focal distribution of virus (Fig. $5 \mathrm{~h}-\mathrm{j}$ ). Although the virus distribution was not quantifiable, it may suggest less spread within areas of infection in the RTL-treated mice. Similar findings were observed in clinical mice. Although high amounts of virus were found in all clinical animals, there was focal distribution in RTL-treated clinical mice (Extended Data Fig. 6e-h). Thus, RTL inhibition of LACV-ND was associated with a decreased amount of CNS virus at later stages of infection.

Effect of RTL on other CSG orthobunyaviruses. We also examined the ability of RTL to inhibit other CSG orthobunyaviruses, namely Jamestown Canyon (JTCV) and Tahyna virus (TAHV). RTL inhibited both JTCV- and TAHV-induced cell death in all cell lines tested (Supplementary Table 1 and Extended Data Fig. 7a,b). RTL treatment significantly reduced JTCV and TAHV viral RNA expression and viral production in SH-SY5Y cells (Extended Data Fig. 7c-f) following the same protocols as for LACV infection (Fig. 1). Thus, RTL inhibited virus replication for multiple CSG orthobunyaviruses. Further studies will be needed to determine whether this inhibition extends to other bunyaviruses as well.

\section{Discussion}

In this study, we utilized a high-throughput screen of FDA-approved drugs and small molecules to identify a compound, RTL, that effectively inhibited LACV replication and neuronal damage. RTL treatment in mice showed that RTL could inhibit LACV-ND even after the virus was already present in the CNS. Thus, RTL appears to inhibit CSG virus-mediated damage of neurons and could be an effective therapeutic for inhibition of CSG virus-induced encephalitis.

The Golgi apparatus has a crucial role in the bunyavirus replication cycle $\mathrm{e}^{20,25,26}$. Following translation of viral mRNA, the two surface glycoproteins, Gn and Gc, associate in heteromultimeric form after precursor polyprotein cleavage in the $\mathrm{ER}^{27,28}$. The transmembrane domains in $\mathrm{Gn}$ help to localize these $\mathrm{Gn}-\mathrm{Gc}$ heteromultimers to the Golgi apparatus ${ }^{20,25,29,30}$. The Golgi Gn-Gc heteromultimers are then inserted into ribonucleoproteins, which are bound to the three segmented viral genomes to form mature virus particles that migrate towards the cell membrane using Golgi-derived vesicles ${ }^{20}$. Our current studies indicate that RTL inhibits migration of LACV at the exit from the Golgi complex, as observed by confocal and TEM analysis. This correlates with the more focal infection in brain tissue observed in RTL-treated mice, suggesting that RTL may work in vivo by preventing neuron-to-neuron transmission of the virus. However, RTL may also limit virus-induced damage by other mechanisms such as by directly interfering with neuronal apoptosis or by affecting glial responses that influence neuronal apoptosis.

The hCO model of LACV infection may provide insight into how RTL could directly inhibit LACV-induced neuronal death in a complex system. We utilized hCOs that lack astrocytes and other 

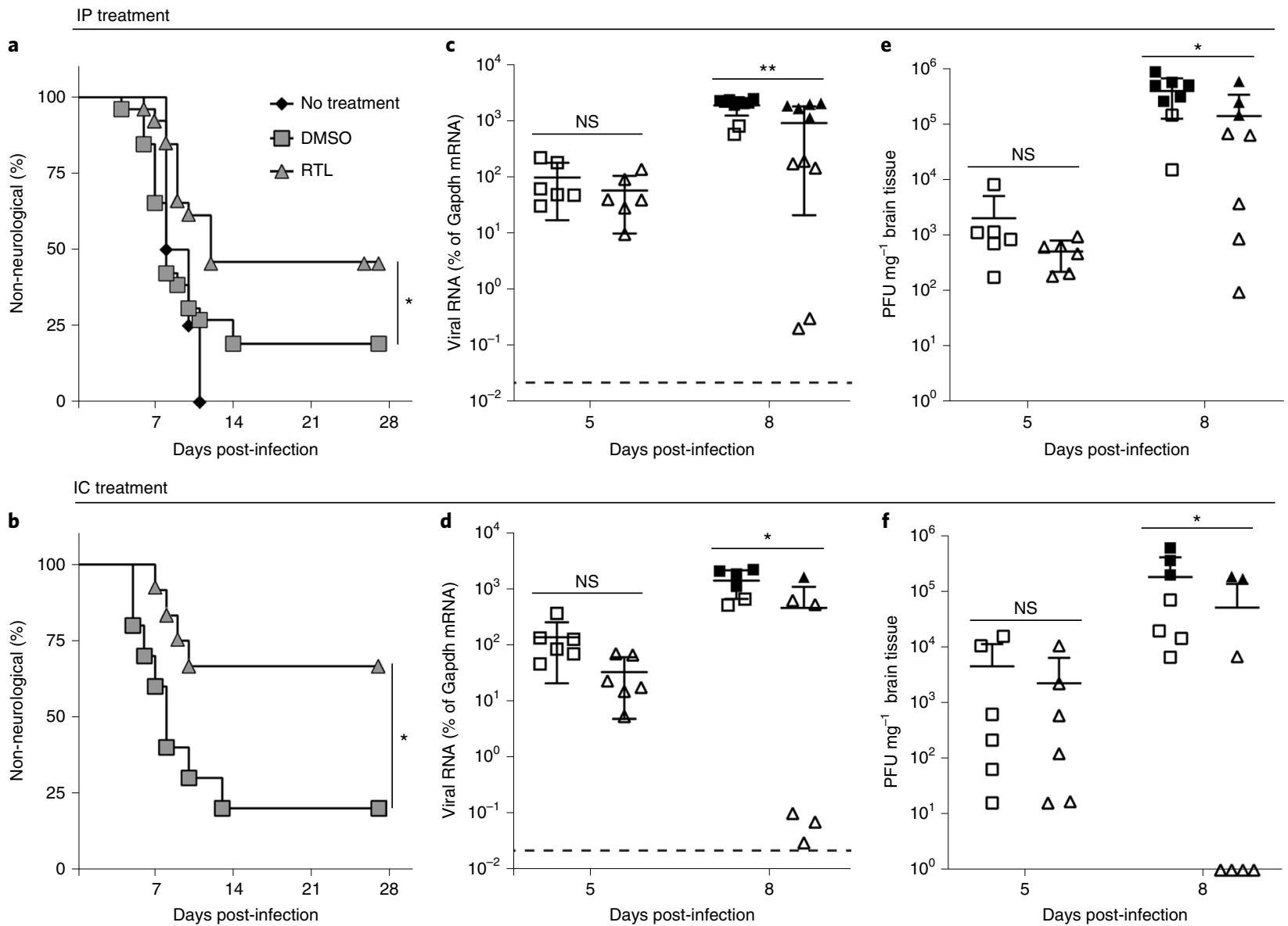

+LACV, -RTL (DMSO)
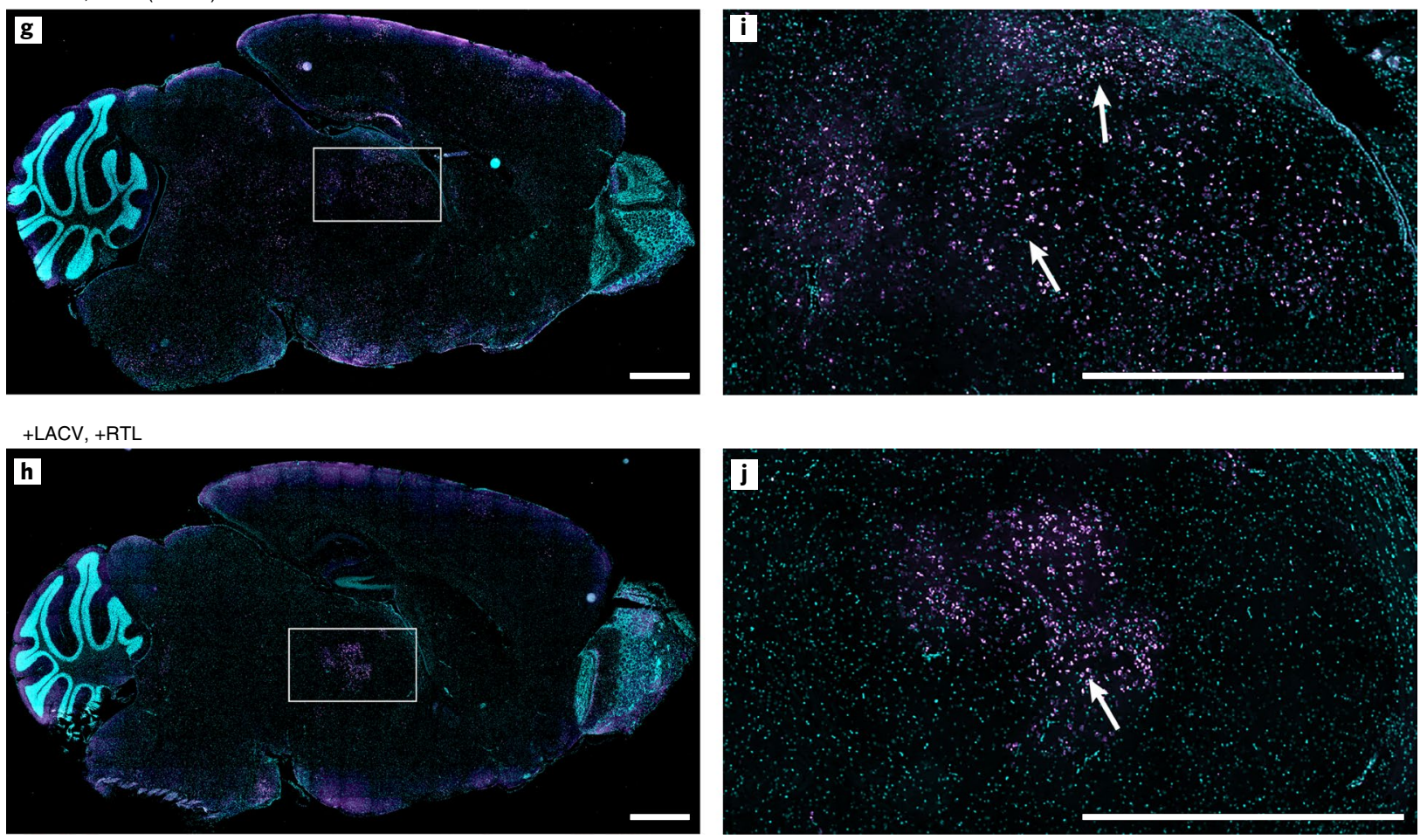

glial cells, which allows the study of virus-induced neuronal damage without the impact of glial cells. RTL treatment reduced virus titres and limited virus-induced growth inhibition of hCOs. Because the
hCOs lack consistent identical structures, we were unable to quantify cellular differences in these organoids. However, the effect of RTL on hCOs appears to be at the level of inhibiting virus replication. 
Fig. 5 | RTL treatment increases survival of LACV-infected mice and reduces viral load in brain tissue. $\mathbf{a}, \mathbf{b}, \mathrm{A}$ mix of male and female MAFIA mice at 22-23 days old were infected with $1 \times 10^{3}$ PFU of LACV by IP administration. For IP drug treatment (a), mice were given RTL (20 mg per kg; $\left.n=26\right)$ or DMSO $(n=26)$ daily for $8 \mathrm{~d}$ starting at $3 \mathrm{dpi}$ and then followed for signs of clinical disease. For IC drug treatment (b), mice were given injections of RTL (250 $\mu$ g per kg; $n=12)$ or DMSO $(n=10)$ at 4 and $7 \mathrm{dpi}$ and followed for the development of clinical disease. Differences in clinical disease were calculated using Kaplan-Meier analysis. The $P$ values for DMSO treatment versus RTL treatment were 0.021 and 0.049 for $\mathbf{a}$ and $\mathbf{b}$, respectively. c-f, To examine viral levels in the CNS, tissues were removed at 5 and $8 \mathrm{dpi}$ and analysed for viral RNA by qRT-PCR (c,d) and infectious virus by plaque assay (e,f). Data are shown as individual animals from two to four different experiments. Lines and error bars for each set indicate mean \pm s.d. Filled symbols indicate clinical animals, and open symbols indicate non-clinical animals. The dashed lines in c,d indicate the cut-off for detection of viral RNA. Animals in $\mathbf{c}, \mathbf{d}$ differ from those in e,f. $P$ values for DMSO treatment versus RTL treatment were $0.0029,0.041,0.04$ and 0.045 for $\mathbf{c}, \mathbf{d}$, e and $\mathbf{f}$, respectively, by Mann-Whitney two-tailed t-test. $\mathbf{g}$-j, Brain tissue from LACV-infected DMSO- $(\mathbf{g}, \mathbf{i})$ or RTL- $(\mathbf{h}, \mathbf{j})$ IP-treated non-clinical mice at 8 dpi. Virus-infected cells are shown in magenta and nuclei are shown in cyan. Scale bars, $1 \mathrm{~mm}$. Cropped images of caudate and thalamus regions (white rectangles) of $\mathbf{g}$ and $\mathbf{h}$, respectively, are shown in $\mathbf{i}$ and $\mathbf{j}$. White arrows indicate areas of virus spread. Images are representative of 3 to 6 mice per group. ${ }^{\star} P<0.05,{ }^{\star \star} P<0.01 ; N S$, not significant.

There was decreased virus replication at early time points PI, which continued over the duration of the experiment. Future studies of LACV-infected hCOs would be useful to determine whether subpopulations of neurons can be more protected by specific drugs.

RTL is a polyphenol (secondary metabolite) isolated from Mallotus philippinensis, which was used as an ancient medicament for its antihelminthic activity in the Ayurvedic medicinal system ${ }^{31}$. RTL has primarily been studied for its ability to inhibit different types of cancer $^{32}$, including glioblastomas and breast cancer. Other studies have indicated potential anti-inflammatory ${ }^{33}$, anti-oxidant ${ }^{34}$, anti-allergic ${ }^{33}$ and antibacterial ${ }^{35}$ effects of RTL. Although originally thought to be a selective inhibitor of protein kinase $C(\mathrm{PKC})-\delta^{36,37}$, in more recent studies RTL inhibited multiple kinases ${ }^{23,38}$ and directly uncoupled mitochondrial respiration, leading to decreased cellular ATP levels ${ }^{38,39}$. ATP is required for multiple steps in vesicular transport. Decreased cellular ATP may be a mechanism by which RTL inhibits anterograde and retrograde transport via the Golgi, rather than through direct inhibition of PKC- $\delta^{23}$. Another drug that disrupts ATP synthesis, carbonyl cyanide-4-(trifluoromethoxy)phenylhydrazone (FCCP), inhibited Semliki Forest virus and Sindbis virus membrane glycoproteins from migrating from the Golgi apparatus to the cell surface ${ }^{40}$. Similarly, RTL inhibition of LACV viral transport from the Golgi may be due, in part, to RTL inhibition of mitochondrial respiration and ATP production.

There were eight compounds in the drug screen that can affect mitochondrial respiration and ATP production. Six of these drugs, metformin, aspirin, sorafenib, tamoxifen, cisplatin and atovaquone, did not significantly inhibit LACV-induced cell death. Two others, itraconazole and ivermectin, had an effect and were in the confirmed screen. Ivermectin was positive in the confirmation run (Extended Data Fig. 1f) but was not among the top three compounds. Ivermectin has potent antiviral activity against multiple viruses $^{41,42}$, although the exact mechanisms remain unknown. The ability of three of the eight compounds that can affect mitochondrial respiration and ATP production to inhibit LACV-induced death of neurons suggests that this may be an important pathway for drug targeting. However, it does not demonstrate that RTL functions through this pathway.

Only a small fraction of LACV infections cause severe neuroinvasive disease ${ }^{2}$. Thus, conducting clinical trials assessing the efficacy of putative therapeutics is limited by patient access. Furthermore, the early common signs of disease such as fever, headache, lethargy and vomiting make early diagnosis of encephalitis difficult ${ }^{2}$. A useful therapeutic drug would need to treat LACV-E at later stages when a clinical diagnosis is made, which would require that the therapeutic cross the blood-brain barrier (BBB). RTL treatment was effective at reducing $L A C V$ disease in mice, even though we delayed treatment until $3 \mathrm{dpi}$, a time where LACV can be found within the $\mathrm{CNS}^{14}$. There are no reports that RTL crosses the BBB, although its ability to treat disease would suggest that it does. Alternatively, RTL may cross the BBB following LACV-induced vascular leakage ${ }^{14}$. Possibly, virus-induced damage to the $\mathrm{BBB}$ may allow RTL or other therapeutics access to the CNS, which is needed to treat encephalitis.

Other molecules, including the nucleoside analogues ribavirin and T-705, have shown antiviral activity against LACV in vitro ${ }^{22,43,44}$. Interestingly, in our study, T-705 was effective in Vero cells but was not very effective in neuronal cells (Table 1 and Extended Data Fig. 2b) or in mice (Extended Data Fig. 6b). The lack of antiviral activity of T-705 may be due to inadequate conversion to its active triphosphate state from the ribonucleotide monophosphate in neuronal cells ${ }^{45}$. In contrast, RTL was highly efficient at inhibiting LACV infection in neuronal cells. The ability of a drug to inhibit virus replication in neurons may help determine whether specific drugs could be useful for the treatment of viral encephalitis, particularly for later stages of disease when infection is primarily found in the CNS.

\section{Methods}

Cell lines. The human neuroblastoma cell line SH-SY5Y (American Type Culture Collection, ATCC) was cultured in Eagle's minimum essential medium (EMEM) and F-12K (Kaighn's modification of Ham's F-12) medium in equal amounts (1:1) supplemented with $10 \%$ FBS. These cells have previously been reported in the literature ${ }^{46}$ to grow in clusters as is observed in Supplementary Fig. $2 \mathrm{~g}, \mathrm{~h}$. H9 human embryonic stem cell-derived hNSCs (ThermoFisher Scientific) were propagated in KnockOut DMEM/F-12 media containing StemPro neural supplement, GlutaMAX-I supplement, fibroblast growth factor and epidermal growth factor. The H9 cells were registered with the National Institutes of Health (NIH) Human Embryonic Stem Cell Registry, and the NIH Guidelines for Human Stem Cell Research were followed. The culture vessels were pre-coated with human plasma fibronectin (Sigma-Aldrich) for growth and experiments of hNSCs. The mouse neuroblastoma cell lines Neuro-2a (N2a) (ATCC) and C17.2 (Sigma-Aldrich) were cultured and maintained in Dulbecco's modified Eagle medium (DMEM) containing 4,500 $\mathrm{mgl}^{-1} \mathrm{D}$-glucose, $\mathrm{L}$-glutamine and $110 \mathrm{mgl}^{-1}$ sodium pyruvate supplemented with $10 \%$ fetal bovine serum (FBS). Vero cells (African green monkey kidney cells, ATCC) were also used for the cell viability study utilizing the MTT (3-(4,5-dimethyl-2-thiazolyl)-2,5-diphenyl-2H-tetrazolium bromide) assay and plaque assays, as well as for viral maintenance and stock production.

Primary neuronal culture. Primary cortical neurons were isolated from the fetuses of pregnant Inbred Rocky Mountain White mice at 14-16 d gestation as previously described ${ }^{47}$. Calcium-free, magnesium-free Hank's balanced salt solution containing $0.125 \%$ trypsin was used to digest the mouse cortices, which were dissociated by repeated pipetting and plated in amine-coated plates (BD Biosciences). After attachment, the neuronal plating medium was replaced with neurobasal medium containing $2 \%$ B-27 and $0.5 \mathrm{mM}$ glutamine and cells were cultured for at least $12 \mathrm{~h}$ before use in experiments.

Small-molecule screening and confirmation. SH-SY5Y cells were seeded $(6,000$ per well) in $12 \mu$ l of growth medium in 384-well plates (Greiner Bio-One), incubated for $24 \mathrm{~h}$, then $23 \mathrm{nl}$ of compounds in DMSO was dispensed per well using pintool transfer before $12 \mu \mathrm{l}$ per well of LACV in growth medium was added $(0.01 \mathrm{MOI})$ and incubated with cells for $6 \mathrm{~d}$. After the 6-d incubation, LACV-induced cytotoxicity was assayed via an ATP-content assay by adding $24 \mu \mathrm{l}$ per well of ATPLite (PerkinElmer) and reading the luminescence signal on a ViewLux (PerkinElmer). A quantitative high-throughput screening (qHTS) was performed on the following libraries: (1) the LOPAC, a collection of 1,280 small molecules with characterized biological activities, purchased from Sigma-Aldrich; and (2) the NCATS Pharmaceutical Collection of small-molecule drugs that were approved in the United States, Canada, the European Union and Japan ${ }^{48}$. 
For the primary screen, each compound was assayed at four concentrations $(9.6 \mu \mathrm{M}, 1.9 \mu \mathrm{M}, 383 \mathrm{nM}$ and $77 \mathrm{nM})$ and percent activity was normalized as $100 \%$ for uninfected SH-SY5Y control and 0\% for SH-SY5Y with virus (Extended Data Fig. 1a). Subsequent selection as detailed in the results section identified NBI 27914, RTL and tyrphostin AG879 as top candidates. All three compounds were purchased from Santa Cruz Biotechnology and the stock solutions were prepared by dissolving $10 \mathrm{mg}$ of each compound in $1 \mathrm{ml}$ DMSO (Sigma-Aldrich) and stored at $-80^{\circ} \mathrm{C}$ for further use.

Cytotoxicity assay. Cells were plated in 96-well plates ( $10^{4}$ cells per well) and different concentrations of each drug were added to each well, in triplicate. DMSO $(0.1 \%)$ and $\mathrm{T}-705^{22}$ were used as negative and positive controls, respectively. At 48-h time intervals, cell viability (MTT) assays were carried out according to the manufacturer's instructions (Invitrogen, ThermoFisher Scientific). This colorimetric assay was used to estimate the cell viability or cytotoxicity and is visualized by $\mathrm{NAD}(\mathrm{P}) \mathrm{H}$-dependent oxidoreductase enzymes of metabolically active cells converting yellow tetrazolium salt to purple formazan crystals. These formazan crystals were dissolved using DMSO and the formazan concentrations were measured using the Synergy 4 cell plate reader (absorbance at $540 \mathrm{~nm}$; BioTek) driven by Gen 5 v1.09.7 software ${ }^{15}$. All absorbances were calculated to measure cell viability using the formula: (sample absorbance/DMSO absorbance $) \times 100 \%$. The $\mathrm{CC}_{50}(50 \%$ cytotoxic concentration) was determined by extrapolating the dose-response curve.

Antiviral efficacy study. Cells ( $10^{4}$ cells per well) were grown in 96-well plates, infected with LACV $(0.1 \mathrm{MOI})$ and treated with different concentrations of test drugs, using DMSO (0.1\%) and T-705 $\left(0-125 \mu \mathrm{g} \mathrm{ml}^{-1}\right)$ as controls. At specific time intervals, the MTT assay was carried out. For SH-SY5Y cells and hNSCs, the MTT assay was measured at $48 \mathrm{hpi}$, while for mouse primary neurons and N2a and C17.2 cells, the MTT assay was performed at 72 hpi. The $\mathrm{EC}_{50}$ of the drug was calculated by plotting dose-dependent curves.

Viral load determination. Cells were cultured in 24 -well plates $\left(2 \times 10^{5}\right.$ cells per well) and infected with LACV (0.1 MOI). At $1 \mathrm{hpi}$, medium was removed and fresh medium containing $\mathrm{EC}_{50}$ and $2 \times \mathrm{EC}_{50}$ concentrations of RTL or DMSO $(0.1 \%)$ was added. At specific time intervals $(6,12$ and $24 \mathrm{~h}$ for RNA expression, and 12, 24 and $48 \mathrm{~h}$ for plaque assay), cell supernatant was removed, centrifuged to eliminate cell debris and frozen at $-80^{\circ} \mathrm{C}$ for plaque assay following the method of Evans et al. ${ }^{16}$, and cells were subjected to RNA isolation for qRT-PCR to determine the viral load inside the cells. Data were analysed using Microsoft Excel v.2102 and converted into graphs, and statistical analysis was completed using GraphPad Prism v.7.04 or v.8.2.0.

RNA isolation, cDNA synthesis and qRT-PCR. RNA was isolated from each well using an RNA isolation kit (Zymo Research). cDNA was synthesized from the RNA samples using an iScript reverse transcription kit (Bio-Rad Laboratories). A fivefold dilution of cDNA samples in RNase-free water was used for qRT-PCR analysis using SYBR Green SuperMix (Bio-Rad Laboratories) using a ViiA 7 instrument and software (v1.2.2) following the method of Butchi et al. ${ }^{47}$. The sequences of the forward and reverse primers were as follows: LACV 'S' gene forward ( $5^{\prime}$-ATTCTACCCGCTGACCATTG-3'), reverse (5'-GTGAGAGTGCCA TAGCGTTG-3'); LACV 'M' gene forward (5'-TTGCCTGGCTGTAAGTGATG-3'), reverse (5'-CAGTCACTTCCTCGGTCTCC-3'); LACV 'L' gene forward (5'-TCT GTGGGTGATTGTGCCTA- $\left.3^{\prime}\right)$, reverse ( $5^{\prime}$-TGCTATGGACACCCATGCTA- $3^{\prime}$ ); JCTV forward (5' ${ }^{\prime}$ TATGGTTCCCCGGTAGTGTG-3'), reverse ( $5^{\prime}$-TAACATGG TGCTTCTCGTGC-3'); TAHV forward ( $5^{\prime}$-AGGTCCTACATTGCCGTTCA-3'), reverse ( $5^{\prime}$-TGGTCTACAGGTGCTAGCTC-3'); mouse Gapdh forward (5'-AACGACCCCTTCATTGAC-3'), reverse (5'-TCCACGACATACTCAGCA-3'); human GAPDH forward (5' - TCGTGGAAGGACTCATGACC- $\left.3^{\prime}\right)$ and reverse $\left(5^{\prime}\right.$-ATGATGTTCTGGAGAGCCCC-3'). Each primer set was reported with the mean of three mock controls. Each viral RNA sample was quantified as the percent variance in cycle threshold $(\mathrm{CyT})$ value $=\mathrm{CyT}$ of GAPDH $-\mathrm{CyT}$ of viral RNA. Data were analysed using Microsoft Excel v.2102 and converted into graphs, and statistical analysis was completed using GraphPad Prism v.7.04 or v.8.2.0.

Confocal microscopy. Cells were grown on eight-well chambered cover glasses (Nunc Lab-Tek, ThermoFisher Scientific) and infected with LACV at $0.1 \mathrm{MOI}$. Cells were treated with either RTL ( $\mathrm{EC}_{50}$ or $2 \times \mathrm{EC}_{50}$ concentrations) or vehicle (DMSO) control at the indicated time points. At $24 \mathrm{hpi}$, cells were washed with PBS and fixed with $4 \%$ paraformaldehyde in PBS. Cells were then permeabilized with $0.01 \%$ Triton X-100 and $0.1 \%$ saponin and blocked with $5 \%$ donkey serum in PBS ('blocking buffer'). Primary antibodies (Supplementary Table 2) were diluted in blocking buffer and incubated at room temperature for $1 \mathrm{~h}$. Cells were labelled with secondary antibodies (Supplementary Table 2) for $1 \mathrm{~h}$ and Hoechst 33342 (Tocris Bioscience) for nuclei staining, and washed with PBS. Samples were imaged using a Zeiss laser scanning confocal microscope (LSM 880) driven by ZEN v.2.3 software (Carl Zeiss Microscopy).

Image processing and analysis. For Fig. 1, image stacks were imported directly into Imaris $\times 86 \_64$ v. 9.5.1 (Bitplane) from ZEN software. The LACV and Hoechst (cell nuclei) signals were segmented using the Surfaces module, and infected cells were identified using a distance transformation filter to the closest LACV signal. For Fig. 3, image stacks were exported from ZEN software and deconvolved with Huygens Professional v.19.04 (Scientific Volume Imaging) using the CMLE algorithm, with $\mathrm{SNR}=20$ and a maximum of 40 iterations. The deconvolved datasets were imported to Imaris for segmentation, surface rendering using the Surfaces module and quantification. The Spots module was used to calculate the total integrated intensity of LACV signal in LACV-infected cells, and a distance transformation filter was applied to generate the subset of LACV integrated intensity within the medial Golgi. The sets of integrated intensity values $(n=397$ cells analysed for vehicle control, and $n=316$ cells analysed for 8 hpi RTL from three independent biological replicates) were imported into Microsoft Excel for data compilation and graphing, and analysed using GraphPad Prism v. 8.2.0.

Time of drug addition assay. SH-SY5Y cells or hNSCs were treated with RTL $\left(2 \times \mathrm{EC}_{50}\right)$ as a pre-treatment, co-treatment, post-treatment or $\mathrm{CT}^{21}$. For pre-treatment, cells were incubated with RTL for $2 \mathrm{~h}$, washed with PBS and then infected with LACV (0.1 MOI) for $1 \mathrm{~h}$, washed again and incubated with normal medium. For co-treatment, cells were simultaneously infected with LACV and treated with RTL for $1 \mathrm{~h}$, after which cells were washed in PBS and fresh medium was added. For post-treatment, cells were infected with LACV for $1 \mathrm{~h}$, washed with PBS and then fresh medium containing RTL was added. For CT, RTL was added $2 \mathrm{~h}$ before infection and then continuously maintained in the culture. For all conditions, cells were incubated at $37^{\circ} \mathrm{C}$ for $2 \mathrm{~d}$ and then MTT assays were carried out as described above. For further analysis of post-addition time points ${ }^{21}$, cells were infected with LACV (0.1 MOI) for $1 \mathrm{~h}$, washed with PBS and then cultured with fresh medium. At intervals of 2, 4, 6, 8 and 12 hpi, this medium was replaced with medium containing RTL $\left(2 \times \mathrm{EC}_{50}\right)$. Cells were analysed at $24 \mathrm{hpi}$ for qRT-PCR or at 48 hpi for MTT assay.

Attachment assay. Cells grown in 24 -well plates $\left(2 \times 10^{5}\right.$ cells per well $)$ were pre-chilled at $4^{\circ} \mathrm{C}$ for $1 \mathrm{~h}$ and subsequently challenged with LACV $(0.1 \mathrm{MOI})$ in the presence of RTL $\left(2 \times \mathrm{EC}_{50}\right)$ or heparin sodium salt (HPR; 1,000, 200 and $\left.40 \mu \mathrm{g} \mathrm{ml}^{-1}\right)$ or DMSO for $3 \mathrm{~h}$ at $4{ }^{\circ} \mathrm{C}$. After infection, the wells were washed twice with ice-cold PBS to remove unbound virus and fresh medium was added. At 1 or $24 \mathrm{hpi}$, qRT-PCR was carried out.

Virus inactivation assay. LACV $\left(10^{6} \mathrm{PFU} \mathrm{ml}^{-1}\right)$ was treated with RTL $\left(2 \times \mathrm{EC}_{50}\right.$ concentration), hyperimmune serum from infected adult mice that had high levels of neutralizing antibodies (Nab; $2.5,0.25$ and $0.025 \mu \mathrm{l}$ ) or DMSO at $37^{\circ} \mathrm{C}$ for $1 \mathrm{~h}$ and then the mixture was diluted 100 -fold with fresh medium to yield a sub-therapeutic concentration of the test compound. The virus inocula were then added to the SH-SY5Y cell monolayer. The 100-fold dilution served to titrate RTL below effective doses and prevent meaningful interactions with the host cell surface. After adsorption for $1 \mathrm{~h}$ at $37^{\circ} \mathrm{C}$, the diluted inocula were discarded, the cells were washed with PBS twice and fresh medium was added. At $24 \mathrm{hpi}$, qRT-PCR was carried out.

TEM. hNSCs were cultured on Thermanox coverslips, infected with LACV $(0.1 \mathrm{MOI})$ and treated with RTL or DMSO at $8 \mathrm{hpi}$. At $24 \mathrm{hpi}$, cells were fixed with $2.5 \%$ glutaraldehyde in $0.1 \mathrm{M}$ sodium cacodylate buffer. All subsequent steps of post-fixation were carried out in a Pelco Biowave microwave (Ted Pella) at $250 \mathrm{~W}$. The cells were dehydrated in a graded ethanol series, infiltrated with Spurr's resin and polymerized in a $60^{\circ} \mathrm{C}$ oven. Ultrathin sections were cut using a Leica UC6 ultramicrotome (Leica Microsystems) and imaged on a Hitachi H7800 instrument (Hitachi High-Technologies) using a Hamamatsu Orca HR camera (Advanced Microscopy Techniques).

hCOs. hCOs were generated, maintained and infected with $1 \times 10^{3}$ PFU LACV in 24 -well culture plates under previously described conditions ${ }^{18}$. At $24 \mathrm{hpi}$, hCOs were treated with RTL at a concentration of $0.1,0.3$ or $1.0 \mu \mathrm{g} \mathrm{ml}^{-1}$ or DMSO in $1 \mathrm{ml}$ of $\mathrm{CO}$ culture medium. Culture supernatant from each organoid was collected every $24 \mathrm{~h}$ through the end of the experiment (6 d) and analysed for infectious virus via plaque assay as previously described. hCOs were also assayed for cell viability daily using a resazurin reduction-based colorimetric assay dye (PrestoBlue, Molecular Probes, ThermoFisher Scientific) as previously described ${ }^{19}$. Data are reported as the percent fluorescence at $590 \mathrm{~nm}$ relative to the $0 \mathrm{dpi}$ baseline taken for each hCO. IHC analysis of hCOs was done at 3 or $6 \mathrm{dpi}$ as described previously ${ }^{18}$. Data were analysed using Microsoft Excel v.2102 and converted into graphs, and statistical analysis was completed using GraphPad Prism v.7.04 or v.8.2.0

Mouse studies. All animal experiments were conducted in compliance with protocols 2016-016 and 2019-23, which were approved by the NIH/NIAID/ RML Institutional Animal Care and Use Committee. For this study, MAFIA mice (C57BL/6-Tg(Csf1r-EGFP-NGFR/FKBP1A/TNFRSF6)2Bck/J stock no. 005070) with fluorescently tagged microglia cells (Csflr expressing) were used to allow for easy detection of microglia activation. A mix of male and female mice were used for all studies and were divided evenly between groups. Group size was determined using GraphPad StatMate with an $80 \%$ power to detect a $40 \%$ increase 
or decrease in disease development. Mice in different litters were randomly assigned to different groups. Mice were housed with a $12 \mathrm{~h} \mathrm{light/dark} \mathrm{cycle} \mathrm{at} \mathrm{a}$ temperature range of $21-24^{\circ} \mathrm{C}$ and a humidity range system set to $50 \% \pm 10 \%$, and were maintained on 2016 Teklad global rodent chow. At 22-24 days old, mice were infected with $1 \times 10^{3} \mathrm{PFU}$ LACV by IP route. At $3 \mathrm{dpi}$, some mice were treated IP with RTL (20 mg per kg), T-705 (250 mg per kg) or DMSO for eight consecutive days. For IC treatment, mice were injected with RTL $\left(250 \mu \mathrm{g} \mathrm{ml}^{-1}\right)$ or DMSO at 4 and 7 dpi using a Hamilton syringe (700 Series syringes, $10-\mu$ l volume) with a 33-gauge needle ${ }^{49}$. For treatment via oral administration, mice were given RTL ( $50 \mathrm{mg}$ per kg) or DMSO once daily for seven consecutive days, starting at $3 \mathrm{dpi}$, using a straight 24-gauge ball-tip disposable feeding needle (Instech). Mice were observed twice daily for 26-30 d for clinical signs of neurologic disease, which primarily included obvious ataxia, limb paralysis and weakness or repeated seizures. Mice showing any of these clinical symptoms were scored as clinical and euthanized for tissue removal. A total of 12 mice were excluded from this study due to issues with either a mistake in virus dose or development of unrelated disease. One experiment was removed completely due to a mistake in the dose of virus inoculation (too low), which included four control mice and five RTL-treated mice with no signs of neurological disease in either group. One mouse was excluded due to genital tract infection before infection and two mice (one DMSO treated and one FPV treated) were removed due to hydrocephaly early on after infection.

Viral load in the CNS. Brain tissues were removed from mice at the initial appearance of clinical signs (as described above) or at 5 and $8 \mathrm{dpi}$. Half of a sagittal section of the brain tissue was stored at $-80^{\circ} \mathrm{C}$ to be used for either RNA or plaque assay. The other half of the sagittal section was immediately placed in $10 \%$ neutral buffer formalin solution and used for IHC to evaluate virus infection. Sectioning of the brains and IHC were performed as previously described ${ }^{16}$. In brief, fixed tissue was embedded in paraffin and sliced in $5-\mu \mathrm{m}$ sections. Slides were deparaffinized, rehydrated and antigen retrieval was conducted in a Decloaking chamber (Biocare Medical) using pH 6 citrate target retrieval solution $(0.1 \mathrm{M}$ citric acid and $0.1 \mathrm{M}$ sodium citrate dehydrate) for $20 \mathrm{~min}$ at $120^{\circ} \mathrm{C}$. Slides were blocked in PBS containing $0.3 \mathrm{M}$ glycine and $5 \%$ donkey serum. Slides were incubated with primary antibodies diluted in blocking buffer at $4{ }^{\circ} \mathrm{C}$ overnight. Slides were then labelled with secondary antibodies for $1 \mathrm{~h}$ and Hoechst 33342. Slides were scanned with a slide scanner (Axio Scan.Z1) using ZEN Blue 3.1 software (Carl Zeiss Microscopy). RNA isolation and qRT-PCR were carried out as described in Woods et al. ${ }^{49}$. For plaque assay, brain tissues were homogenized at 5,300 r.p.m. for $25 \mathrm{~s}$ in a homogenizer (Bead Mill 24, Fisher Scientific) in the presence of DMEM. Samples were then centrifuged at 5,000 $\mathrm{g}$ for $10 \mathrm{~min}$ and supernatants were transferred into a new tube. Samples were then diluted to $10^{-1}$ to $10^{-7}$ in DMEM containing $10 \%$ FBS before being used in a plaque assay ${ }^{16}$.

Statistical analysis. For in vitro studies, no statistical methods were used to pre-determine sample sizes, but our sample sizes are similar to those reported in previous publications $s^{15,16}$. All in vitro experiments were set up in triplicate samples with two to three repeated experiments. This provides controls for both in-experiment and between-experiment variation. For mouse studies, StatMate was used to calculate the number of animals to complete the studies using a predicted $80 \%$ of mice developing clinical signs of disease, and an $80 \%$ power to detect a $30 \%$ decrease in survival proportion with a significance level of 0.05 (two-tailed analysis in case the results were opposite to what we expected). All post-study statistical analysis was performed using GraphPad Prism v.7.04 and v.8.02. In each case, $P$ values are represented as ${ }^{\star} P<0.05,{ }^{* *} P<0.01,{ }^{* * *} P<0.001$ and ${ }^{* * * *} P<0.0001$. Specific analysis information is described in the figure legends. Exact $P$ values are presented in Supplementary Table 3.

Reporting Summary. Further information on research design is available in the Nature Research Reporting Summary linked to this article.

\section{Data availability}

The data that support the findings of this study are available from the corresponding author upon request. The primary screening data have been made publicly available as PubChem bioassay assay ID (AID) 1508616 . Source data are provided with this paper.

Received: 8 October 2020; Accepted: 25 August 2021;

Published online: 21 October 2021

\section{References}

1. Calisher, C. H. Medically important arboviruses of the United States and Canada. Clin. Microbiol. Rev. 7, 89-116 (1994).

2. Rust, R. S. et al. Topical review: La Crosse and other forms of California encephalitis. J. Child. Neurol. 14, 1-14 (1999).

3. Thompson, W. H., Kalfayan, B. \& Anslow, R. O. Isolation of California encephalitis group virus from a fatal human illness. Am. J. Epidemiol. 81, 245-253 (1965).
4. Thompson, W. H. \& Gundersen, C. B. La Crosse encephalitis: occurrence of disease and control in a suburban area. Prog. Clin. Biol. Res. 123, 225-236 (1983).

5. Lambert, A. J. et al. Comparative sequence analyses of La Crosse virus strain isolated from patient with fatal encephalitis, Tennessee, USA. Emerg. Infect. Dis. 21, 833-836 (2015).

6. Gauld, L. W., Yuill, T. M., Hanson, R. P. \& Sinha, S. K. Isolation of La Crosse virus (California encephalitis group) from the chipmunk (Tamias striatus), an amplifier host. Am. J. Trop. Med. Hyg. 24, 999-1005 (1975).

7. Evans, A. B. \& Peterson, K. E. Throw out the map: neuropathogenesis of the globally expanding California serogroup of orthobunyaviruses. Viruses 11, 794 (2019).

8. Baldridge, G. D., Beaty, B. J. \& Hewlett, M. J. Genomic stability of La Crosse virus during vertical and horizontal transmission. Arch. Virol. 108, 89-99 (1989).

9. McJunkin, J. E. et al. Safety and pharmacokinetics of ribavirin for the treatment of La Crosse encephalitis. Pediatr. Infect. Dis. J. 30, 860-865 (2011)

10. Centers for Disease Control and Prevention. La Crosse encephalitis (2018); https://www.cdc.gov/lac/index.html

11. Bennett, R. S. et al. A recombinant chimeric La Crosse virus expressing the surface glycoproteins of Jamestown Canyon virus is immunogenic and protective against challenge with either parental virus in mice or monkeys. J. Virol. 86, 420-426 (2012).

12. Taylor, K. G. et al. Age-dependent myeloid dendritic cell responses mediate resistance to La Crosse virus-induced neurological disease. J. Virol. 88, 11070-11079 (2014).

13. Winkler, C. W. et al. Lymphocytes have a role in protection, but not in pathogenesis, during La Crosse virus infection in mice. J. Neuroinflammation 14, 62 (2017)

14. Winkler, C. W., Race, B., Phillips, K. \& Peterson, K. E. Capillaries in the olfactory bulb but not the cortex are highly susceptible to virus-induced vascular leak and promote viral neuroinvasion. Acta Neuropathol. 130, 233-245 (2015).

15. Mukherjee, P., Woods, T. A., Moore, R. A. \& Peterson, K. E. Activation of the innate signaling molecule MAVS by bunyavirus infection upregulates the adaptor protein SARM1, leading to neuronal death. Immunity $\mathbf{3 8}$, 705-716 (2013)

16. Evans, A. B., Winkler, C. W. \& Peterson, K. E. Differences in neuropathogenesis of encephalitic California serogroup viruses. Emerg. Infect. Dis. 25, 728-738 (2019).

17. Dawes, B. E. et al. Human neural stem cell-derived neuron/astrocyte co-cultures respond to La Crosse virus infection with proinflammatory cytokines and chemokines. J. Neuroinflammation 15, 315 (2018).

18. Winkler, C. W. et al. Neuronal maturation reduces the type I IFN response to orthobunyavirus infection and leads to increased apoptosis of human neurons. J. Neuroinflammation 16, 229 (2019).

19. Hollidge, B. S. et al. Orthobunyavirus entry into neurons and other mammalian cells occurs via clathrin-mediated endocytosis and requires trafficking into early endosomes. J. Virol. 86, 7988-8001 (2012).

20. Elliott, R. E. Orthobunyaviruses: recent genetic and structural insights. Nat. Rev. Microbiol. 12, 673-685 (2014).

21. Lin, L. T. et al. Hydrolyzable tannins (chebulagic acid and punicalagin) target viral glycoprotein-glycosaminoglycan interactions to inhibit herpes simplex virus 1 entry and cell-to-cell spread. J. Virol. 85, 4386-4398 (2011).

22. Gowen, B. B. et al. In vitro and in vivo activities of T-705 against arenavirus and bunyavirus infections. Antimicrob. Agents Chemother. 51, 3168-3176 (2007)

23. Sugawara, T. et al. PKC $\delta$ and $\varepsilon$ regulate the morphological integrity of the ER-Golgi intermediate compartment (ERGIC) but not the anterograde and retrograde transports via the Golgi apparatus. Biochim. Biophys. Acta 1823, 861-875 (2012)

24. Zhang, D., Anantharam, V., Kanthasamy, A. \& Kanthasamy, A. G. Neuroprotective effect of protein kinase $C \delta$ inhibitor rottlerin in cell culture and animal models of Parkinson's disease. J. Pharmacol. Exp. Ther. 322, 913-922 (2007).

25. Gerrard, S. R. \& Nichol, S. T. Characterization of the Golgi retention motif of Rift Valley Fever virus $\mathrm{G}_{\mathrm{N}}$ glycoprotein. J. Virol. 76, 12200-12210 (2002).

26. Fontana, J. et al. The unique architecture of Bunyamwera virus factories around the Golgi complex. Cell. Microbiol. 10, 2012-2028 (2008).

27. Bupp, K., Stillmock, K. \& González-Scarano, F. Analysis of the intracellular transport properties of recombinant La Crosse virus glycoproteins. Virology 220, 485-490 (1996).

28. Eshita, Y. \& Bishop, D. H. The complete sequence of the M RNA of snowshoe hare bunyavirus reveals the presence of internal hydrophobic domains in the viral glycoprotein. Virology 137, 227-240 (1984).

29. Bertolotti-Ciarlet, A. et al. Cellular localization and antigenic characterization of Crimean-Congo hemorrhagic fever virus glycoproteins. J. Virol. 79, 6152-6161 (2005) 
30. Haferkamp, S. et al. Intracellular localization of Crimean-Congo Hemorrhagic Fever (CCHF) virus glycoproteins. Virol. J. 2, 42 (2005).

31. Srivastava, M. C., Singh, S. W. \& Tewari, J. P. Anthelmintic activity of Mallotus philippinensis-kambila powder. Ind. J. Med. Res. 55, 746-748 (1967).

32. $\mathrm{Su}$, J. et al. Rottlerin exhibits anti-cancer effect through inactivation of $\mathrm{S}$ phase kinase-associated protein 2 in pancreatic cancer cells. Am. J. Cancer Res. 6, 2178-2191 (2016).

33. Ishii, R. et al. Inhibition of lipopolysaccharide-induced pro-inflammatory cytokine expression via suppression of nuclear factor-kappaB activation by Mallotus japonicus phloroglucinol derivatives. Biochim. Biophys. Acta 1620, 108-118 (2003).

34. Maioli, E. et al. Rottlerin inhibits ROS formation and prevents NFkappaB activation in MCF-7 and HT-29 cells. J. Biomed. Biotechnol. 2009, 742936 (2009)

35. Zaidi, S. F. et al. Potent bactericidal constituents from Mallotus philippinensis against clarithromycin and metronidazole resistant strains of Japanese and Pakistani Helicobacter pylori. Biol. Pharm. Bull. 32, 631-636 (2009).

36. Gschwendt, M. et al. Rottlerin, a novel protein kinase inhibitor. Biochem. Biophys. Res. Commun. 199, 93-98 (1994).

37. Bain, J. et al. The selectivity of protein kinase inhibitors: a further update Biochem. J. 408, 297-315 (2007).

38. Soltoff, S. P. Rottlerin is a mitochondrial uncoupler that decreases cellular ATP levels and indirectly blocks protein kinase Cdelta tyrosine phosphorylation. J. Biol. Chem. 276, 37986-37992 (2001).

39. Lei, L., Li, Z. \& Zhong, G. Rottlerin-mediated inhibition of Chlamydia trachomatis growth and uptake of sphingolipids is independent of p38-regulated/activated protein kinase (PRAK). PLoS ONE 7, e44733 (2012)

40. Kääriäinen, L. et al. Monensin and FCCP inhibit the intracellular transport of alphavirus membrane glycoproteins. J. Cell Biol. 87, 783-791 (1980).

41. Yang, S. N. Y. et al. The broad spectrum antiviral ivermectin targets the host nuclear transport importin $\alpha / \beta 1$ heterodimer. Antiviral Res. 177, 104760 (2020)

42. Jans, D. A. \& Wagstaff, K. M. Ivermectin as a broad-spectrum host-directed antiviral: the real deal? Cells 9, 2100 (2020).

43. Cassidy, L. F. \& Patterson, J. L. Mechanism of La Crosse virus inhibition by ribavirin. Antimicrob. Agents Chemother. 33, 2009-2011 (1989).

44. Smith, D. R. et al. Development of FGI-106 as a broad-spectrum therapeutic with activity against members of the family Bunyaviridae. Virus Adapt. Treat. 2, 9-20 (2010).

45. Huchtingab, J. et al. Cell line-dependent activation and antiviral activity of T-1105, the non-fluorinated analogue of T-705 (favipiravir). Antiviral Res. 167, 1-5 (2019).

46. Kovalevich, J. \& Langford, D. et al. Considerations for the use of SH-SY5Y neuroblastoma cells in neurobiology. Methods Mol. Biol. 1078, 9-21 (2013).

47. Butchi, N. B. et al. TLR7 and TLR9 trigger distinct neuroinflammatory responses in the CNS. Am. J. Pathol. 179, 783-794 (2010).
48. Huang, R. et al. The NCATS Pharmaceutical Collection: a 10-year update. Drug Discov. Today 24, 2341-2349 (2019).

49. Woods, T. A., Du, M., Carmody, A. \& Peterson, K. E. Neuropeptide Y negatively influences monocyte recruitment to the central nervous system during retrovirus infection. J. Virol. 90, 2783-2793 (2016).

\section{Acknowledgements}

We thank P. Policastro and A. B. Evans for assistance with cells, virus cultures and antibody preparation, and T. Starr for confocal microscopy assistance; A. Mora, R. Kissinger and the graphics art unit at RML for graphics assistance and figure preparation; B. Caughey, L. H. Evans, A. Chong and A. I. Chiramel for review of the manuscript; D. Long for assistance with tissue section preparations and H\&E staining, and L. Lubke for light microscopy imaging; and the Rocky Mountain Veterinary Branch for their excellent animal husbandry and assistance. This work was supported by the Division of Intramural Research, National Institutes of Health, National Institute of Allergy and Infectious Diseases, 1ZIAAI001102-09 (K.E.P.). The funder had no role in study design, data collection and analysis, decision to publish or preparation of the manuscript.

\section{Author contributions}

K.T., D.O. and K.E.P. conceived the idea and designed the experiments. C.Z.C., C.D.Y., G.J.T. and W.Z. completed the initial and secondary screens of the compounds. D.O., C.W.W., J.M.L., T.A.W., V.N., C.L.L. and C.L.H. completed the final screens, examined the mechanisms of RTL inhibition and completed the organoid and animal studies. D.O. and K.E.P. wrote the manuscript. D.O., C.W.W., J.M.L., T.A.W., C.Z.C., V.N., C.L.H. and K.E.P. helped revise and edit the manuscript.

\section{Competing interests}

The authors declare no competing interests.

\section{Additional information}

Extended data is available for this paper at https://doi.org/10.1038/s41564-021-00968-y.

Supplementary information The online version contains supplementary material available at https://doi.org/10.1038/s41564-021-00968-y.

Correspondence and requests for materials should be addressed to Karin E. Peterson.

Peer review information Nature Microbiology thanks Juan Carlos de la Torre, Masayuk Saijo and the other, anonymous, reviewer(s) for their contribution to the peer review of this work. Peer reviewer reports are available.

Reprints and permissions information is available at www.nature.com/reprints. Publisher's note Springer Nature remains neutral with regard to jurisdictional claims in published maps and institutional affiliations.

This is a U.S. government work and not under copyright protection in the U.S.; foreign copyright protection may apply 2021 
a
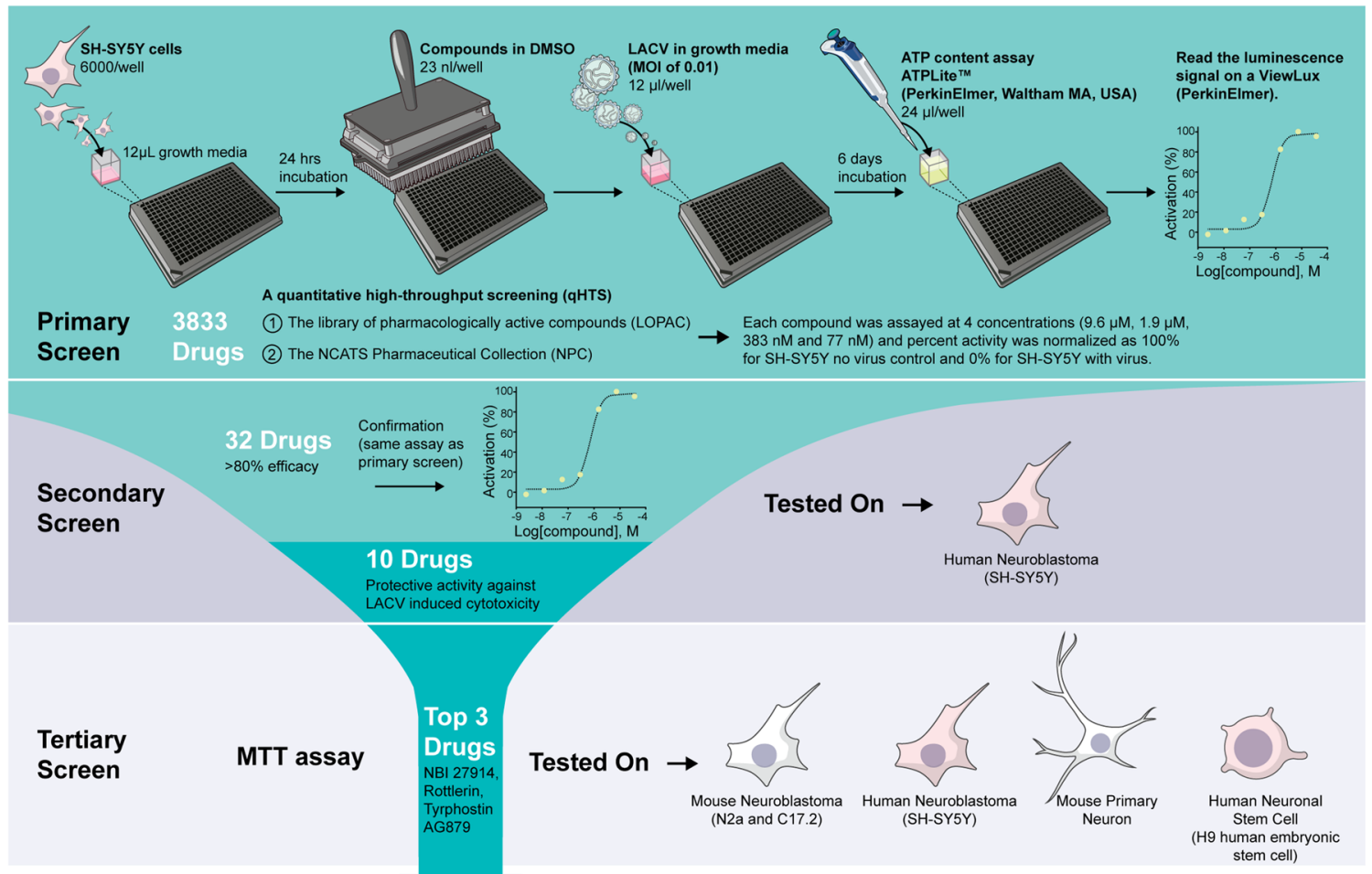

1 Drug $\rightarrow$ Rottlerin
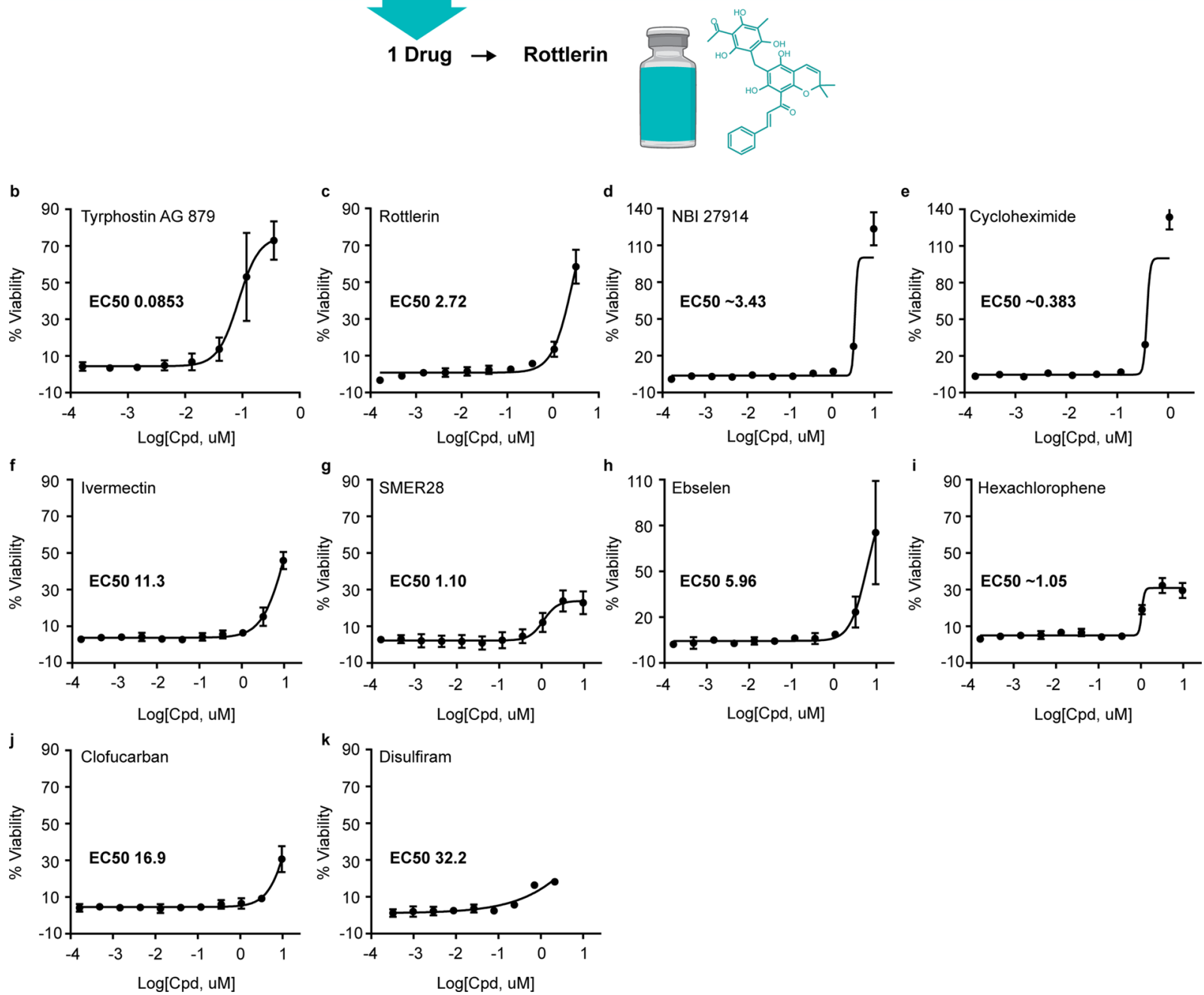

Extended Data Fig. 1 | See next page for caption. 
Extended Data Fig. 1 | (a) Schematic diagram of detailed drug screening methods. (b-k) Anti-LACV activity of (b) tyrphostin AG879, (c) rottlerin, (d) NBI 27914, (e) cycloheximide, (f) ivermectin, (g) SMER 28, (h) ebselen, (i) hexachlorophene, (j) clofucarban and (k) disulfiram on SH-SY5Y cells. SHSY5Y cells were grown on 384-well plates. Cells were pretreated with experimental compounds or control. Approximately $1 \mathrm{~h}$ after addition of compounds, LACV (0.01 MOI) was added to each well. After 6 days of incubation, ATPlite ${ }^{\text {TM }}$ reagent was added to assay ATP content as a measure of cell viability. The $\%$ activity plotted was calculated as: $\%$ activity $=($ Signal - Min $) /($ Max - Min $) \times 100$; where Max =SH-SY5Y without virus; Min =SH-SY5Y infected with virus. Each symbol represents the mean \pm SD of six wells from two independent experiments. 


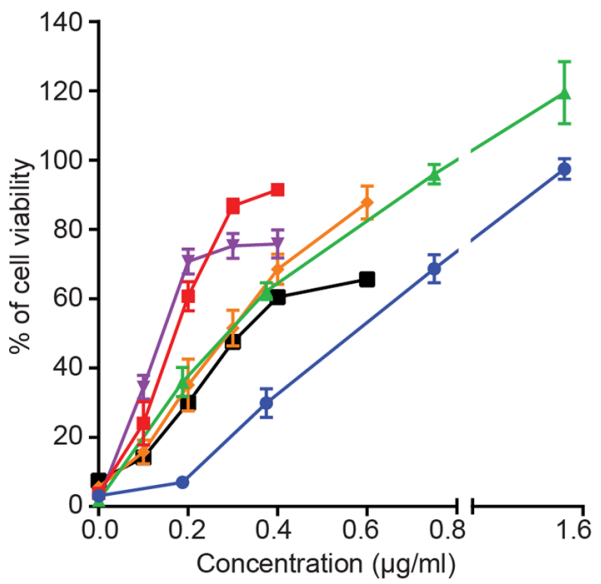

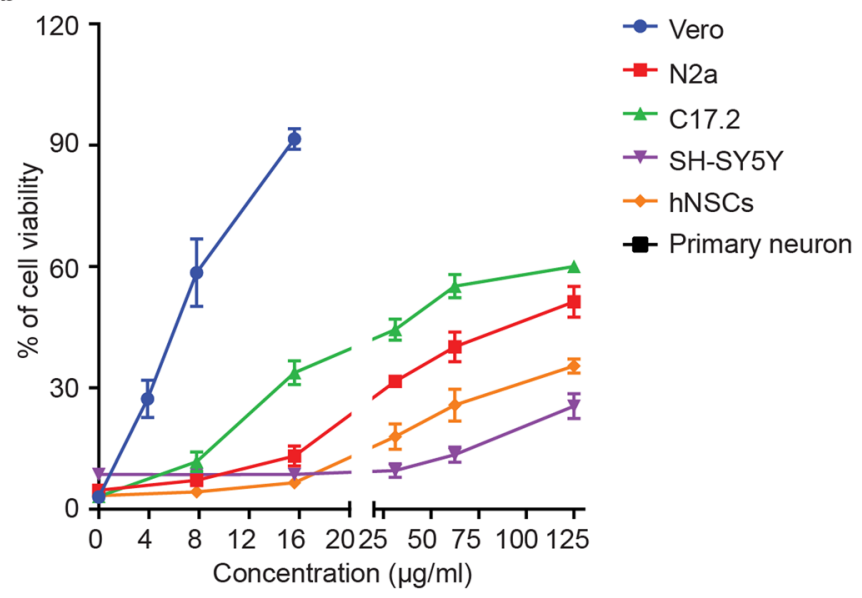
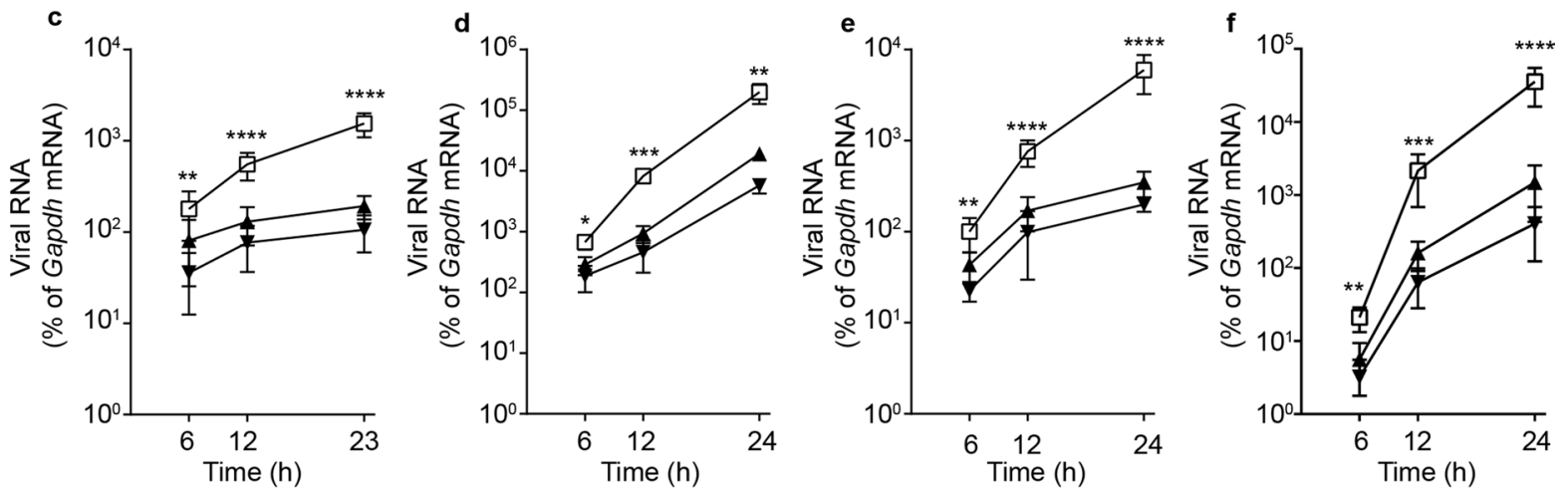

छ VC $(\mathrm{DMSO}) \quad \Delta \mathrm{RTL}\left(\mathrm{EC}_{50}\right) \quad \boldsymbol{\mathrm { RTL }}\left(2 \times \mathrm{EC}_{50}\right)$

g
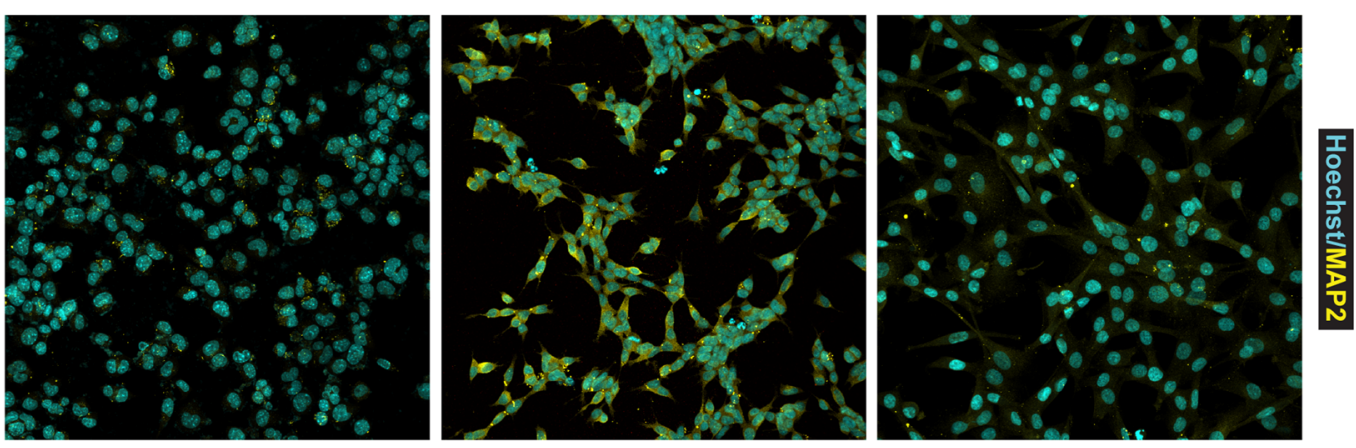

h

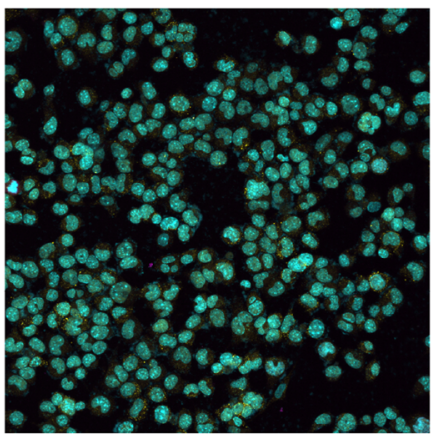

N2a

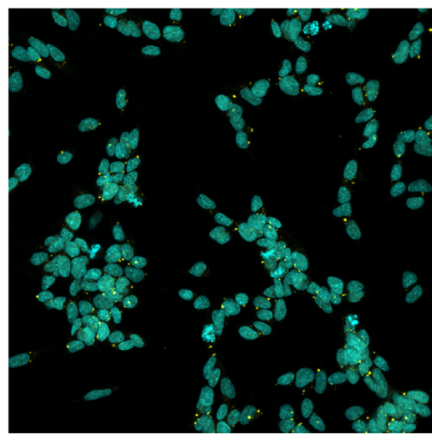

SH-SY5Y

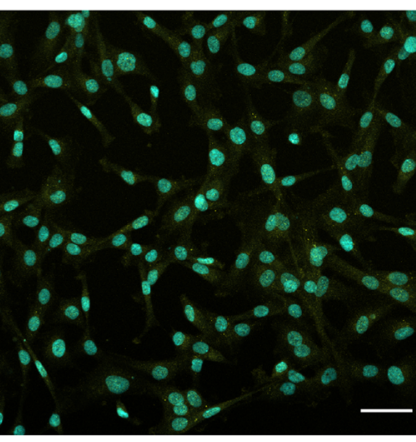

hNSCs

Extended Data Fig. 2 | See next page for caption. 
Extended Data Fig. 2 | (a, b) Dose-dependent anti-LACV activity of (a) RTL and (b) T-705 on Vero, N2a, C17.2, SH-SY5Y, hNSCs, and mouse primary neurons. Cells ( $10^{4}$ cells/well) were plated in 96-well plates and infected with LACV (MOI 0.1) for one hour. Cells were then treated with different concentrations of (a) RTL and (b) T-705 using DMSO (0.1\%) as control. At specific time intervals ( $72 \mathrm{~h}$ for rodent-derived cells and $48 \mathrm{~h}$ for humanderived cells), an MTT assay was carried out as described in the methods. Each symbol represents the mean \pm SD of nine wells combined from three independent experiments except for mouse primary neurons where error bars represent three individuals well of a single experiment. (c-f) Anti-LACV activity of RTL in multiple neuronal cell lines. Viral RNA expression in (c) N2a, (d) mouse primary neuron, (e) SH-SY5Y and ( $f$ ) hNSCs. Cells were infected with LACV for 1 hour followed by RTL treatment at $\mathrm{EC}_{50}$ and $2 \times \mathrm{EC}_{50}$ doses. At 6, 12 and 24 hpi, RNA was isolated from cells for qRT-PCR analysis. Each symbol represents the mean \pm SD of nine individual wells per cell type combined from 3 independent experiments, except for primary neurons where data are from three individuals well of a single experiment. ${ }^{\star} \mathrm{P}<0.05$; ${ }^{\star \star} \mathrm{P}<0.01$; ${ }^{\star \star \star} \mathrm{P}<0.001$ and ${ }^{\star \star \star \star} \mathrm{P}<0.0001$; Statistics were done with a One-way ANOVA at each time point by Dunnett's multiple comparisons test. The percentage viral RNA expression of cell control (CC; mock control) were between $10^{-1}$ to $10^{-3}$. ( $(\mathrm{g}, \mathrm{h})$ Immunofluorescence labelling with $(\mathrm{g})$ MAP2 and $(\mathrm{h})$ NeuN of uninfected untreated N2a, SH-SY5Y, hNSCs cells. MAP2 and NeuN signal are shown in yellow and host cell nuclei is shown in cyan. Scale bar, $50 \mu \mathrm{m}$. Images are representative of 2 replicate experiments. 

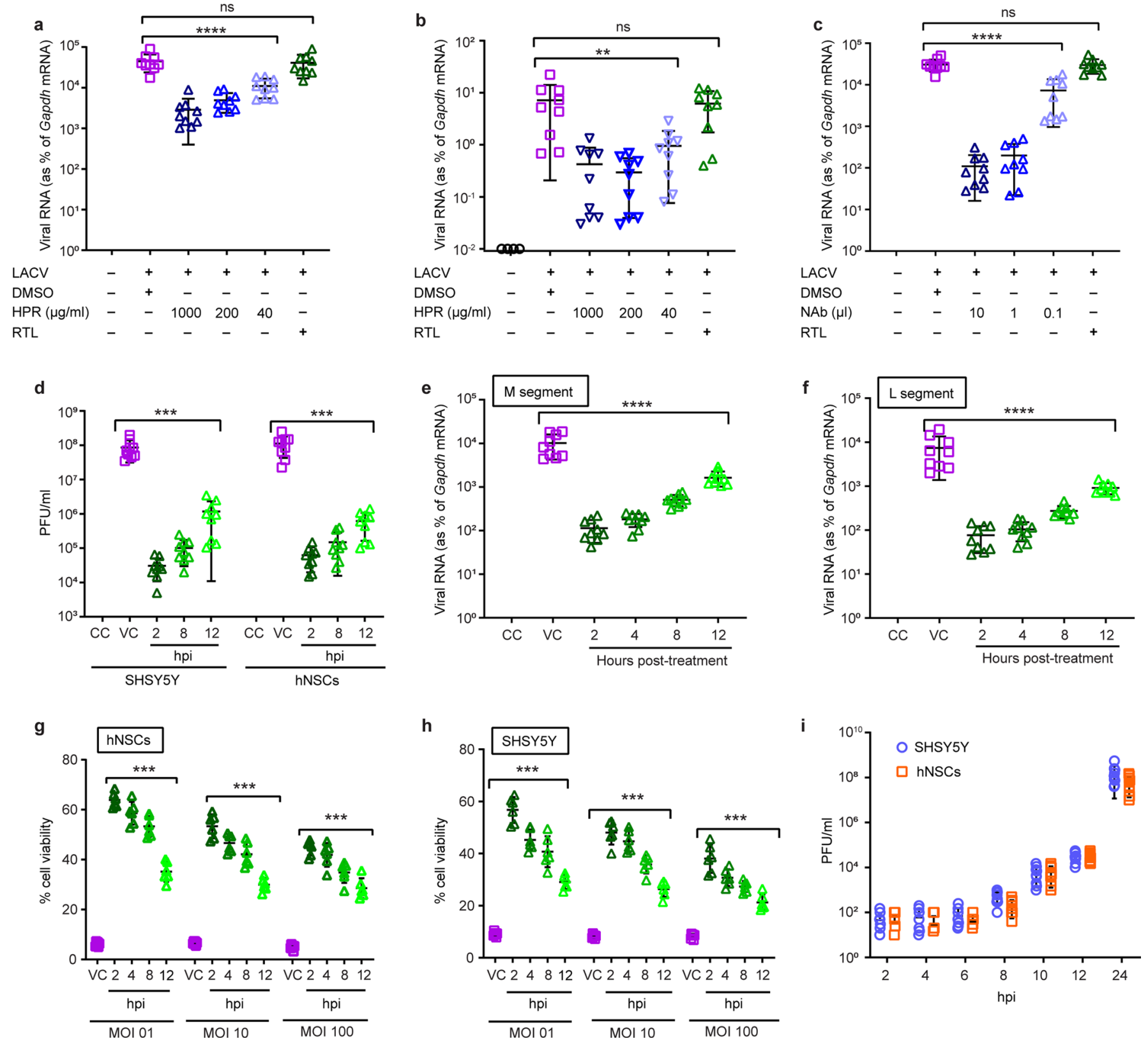

Extended Data Fig. 3 | See next page for caption. 
Extended Data Fig. 3 | Time kinetics study of RTL and virus replication kinetics. (a, b) Effect of RTL on virus attachment in SH-SY5Y cells. Prechilled $\mathrm{SH}-\mathrm{SH} 5 Y$ cells were infected with LACV (MOI 0.1) mixed with RTL, heparin sodium salt or DMSO. HPR and DMSO were used as the positive and negative control respectively. After $3 \mathrm{~h}$ at $4{ }^{\circ} \mathrm{C}$ incubation, the cells were washed twice with ice-cold PBS and fresh media added. After (b) 1 or (a) $24 \mathrm{hpi}$ qRT-PCR was carried out. Line with error bars indicates the mean \pm SD for nine data points (symbols) of three independent experiments for each group. ${ }^{\star \star} \mathrm{P}<0.01$ and ${ }^{\star \star \star \star} P<0.0001$; by one-way ANOVA using Dunnett's multiple comparisons test. (c) Virus inactivation assay of RTL on SH-SY5Y cells. RTL ( $2 \times E C_{50}$ concentration), neutralizing antibody (NAb; $2.5,0.25$, and $0.025 \mu \mathrm{l}$ ) or DMSO was preincubated with LACV $\left(10^{6} \mathrm{PFU}\right)$ at $37^{\circ} \mathrm{C}$ for $1 \mathrm{~h}$. NAb and DMSO were used as a positive and negative control respectively. Then the mixture was diluted 100 -fold and added to the SH-SY5Y cells monolayer. After $1 \mathrm{~h}$ at $37{ }^{\circ} \mathrm{C}$ incubation, the cells were washed with PBS twice and fresh media added. After 24 hpi incubation qRT-PCR was carried out. Line with error bars indicates the mean $\pm S D$ for nine data points (symbols) of three independent experiments for each group. ${ }^{\star \star \star \star} P<0.0001$; by One-way ANOVA using Dunnett's multiple comparisons test. (d) Extracellular virus production in cell supernatant in RTL treatment after 2, 8 and 12 hpi. Cells were infected with LACV (MOI 0.1) for $1 \mathrm{~h}$, washed with PBS, and then cultured with fresh media. At intervals of 2, 8 and 12 hpi, this media was replaced with media containing RTL $\left(2 \times E C_{50}\right)$. At 24 hpi, cell supernatants were harvested and titered by plaque assay. Line with error bars indicates the mean \pm SD for nine data points (symbols) of three independent experiments for each group. ${ }^{\star \star \star} \mathrm{P}<0.001$ by Two-way ANOVA using Sidak's multiple comparisons test. $(e, f)$ Time of RTL addition on post-infection at different time intervals ( $2 h, 4 h, 8 h$ and $12 h$ ) measuring (e) M and (f) L segment RNA expression. Experiments were performed following the same protocols as for Fig. 1k. Line with error bars indicates the mean \pm SD for nine data points (symbols) of three independent experiments for each group. ${ }^{\star \star \star \star} \mathrm{P}<0.0001$; by One-way ANOVA using Dunnett's multiple comparisons test. CC indicates cell control (mock control) and VC indicates vehicle control. $(\mathrm{g}, \mathrm{h})$ Time of RTL addition on post-infection at different MOI $(1$ to 100$)$ as well as different time interval ( $\mathbf{h}, \mathbf{4 h}, \mathbf{8} \mathrm{h}$ and $\mathbf{1 2} \mathrm{h}$ ) by MTT assay. (g) SH-SY5Y cells and (h) hNSCs were infected with LACV at 1,10 and $100 \mathrm{MOI}$ for $1 \mathrm{~h}$, washed with PBS, and then cultured with fresh media. At intervals of $2,4,8$ and 12 hpi, media was replaced with media containing RTL ( $\left.2 \times E C_{50}\right)$. At 48 hpi MTT assay was carried out and cell viability was measured following previously described methods. Data are shown for six individual data points from two independent experiments with the mean $\pm S D$. ${ }^{\star * *} P<0.001$; by two-way ANOVA with Tukey's multiple comparisons. (i) Virus release curves at different time intervals. hNSCs and SH-SY5Y cell monolayers ( $1 \times 10^{5}$ cells/well) were infected with LACV (MOI 0.1) and allowed to absorb for $1 \mathrm{~h}$. The inoculum was removed, and the cells were rinsed with PBS three times prior to the addition of fresh growth medium. At intervals post-infection, the media were collected separately, clarified by centrifugation, and frozen at $-80^{\circ} \mathrm{C}$. The virus titre in each sample were determined by plaque assay. Data are shown for the individual samples from three independent experiments along with a line indicating the mean \pm SD bars. 
a

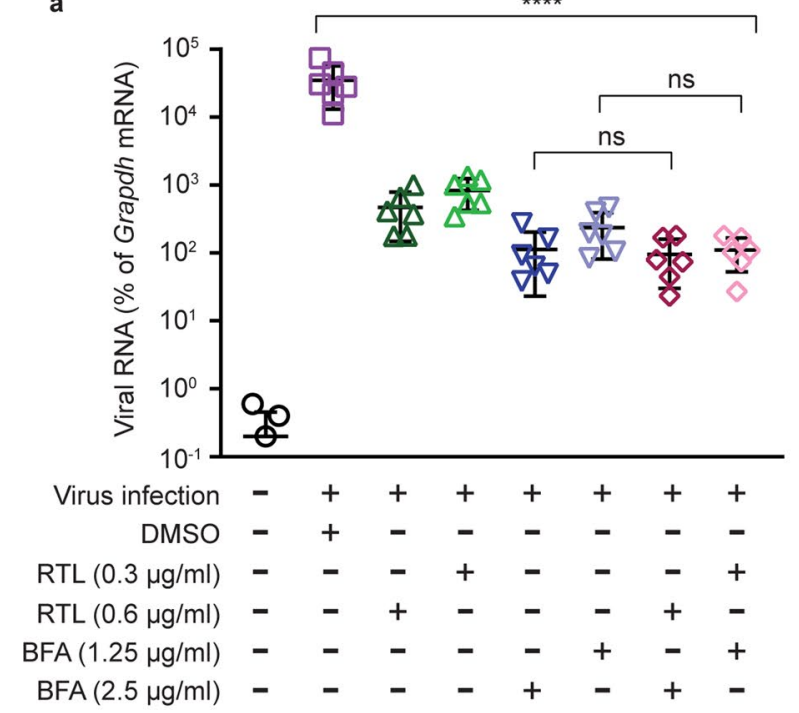

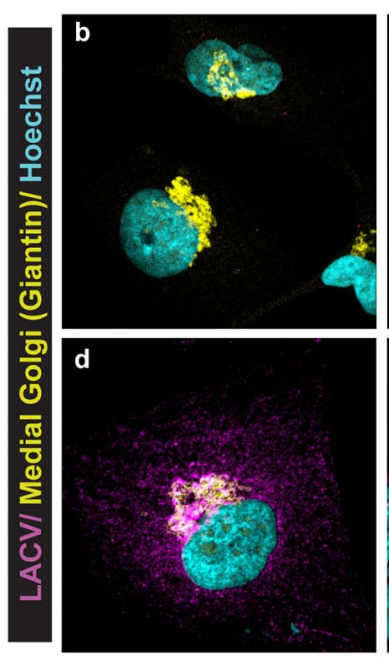

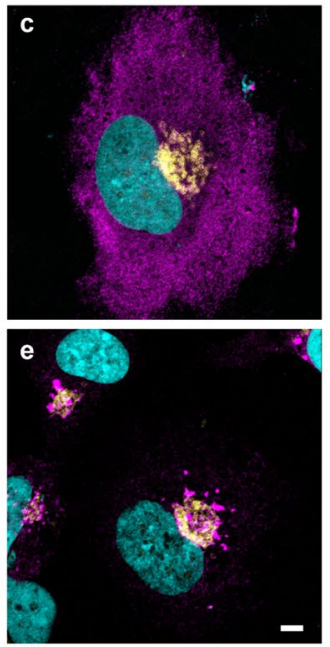

f

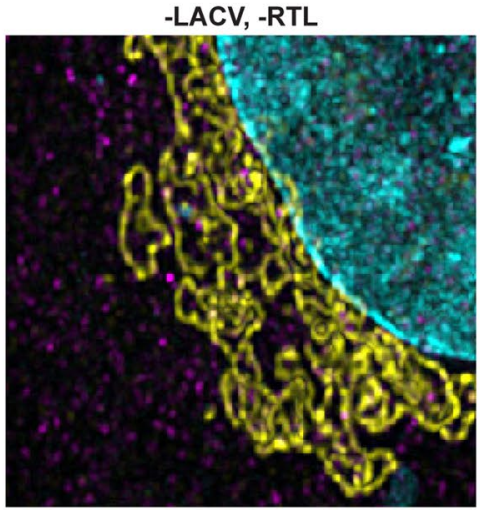

g

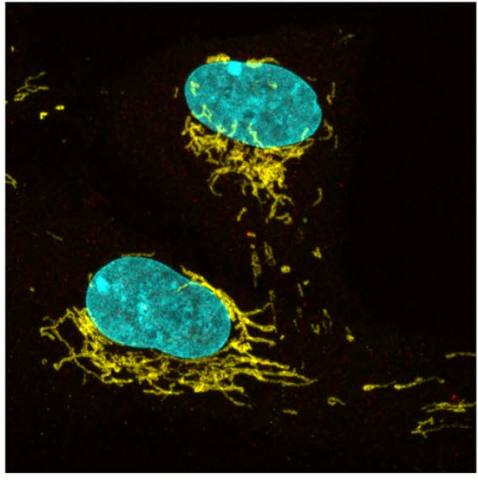

h

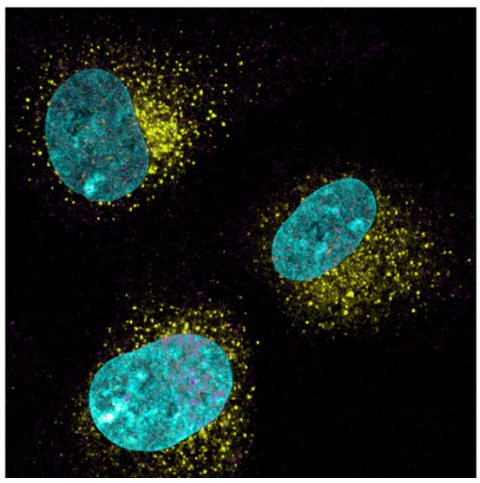

+LACV, -RTL
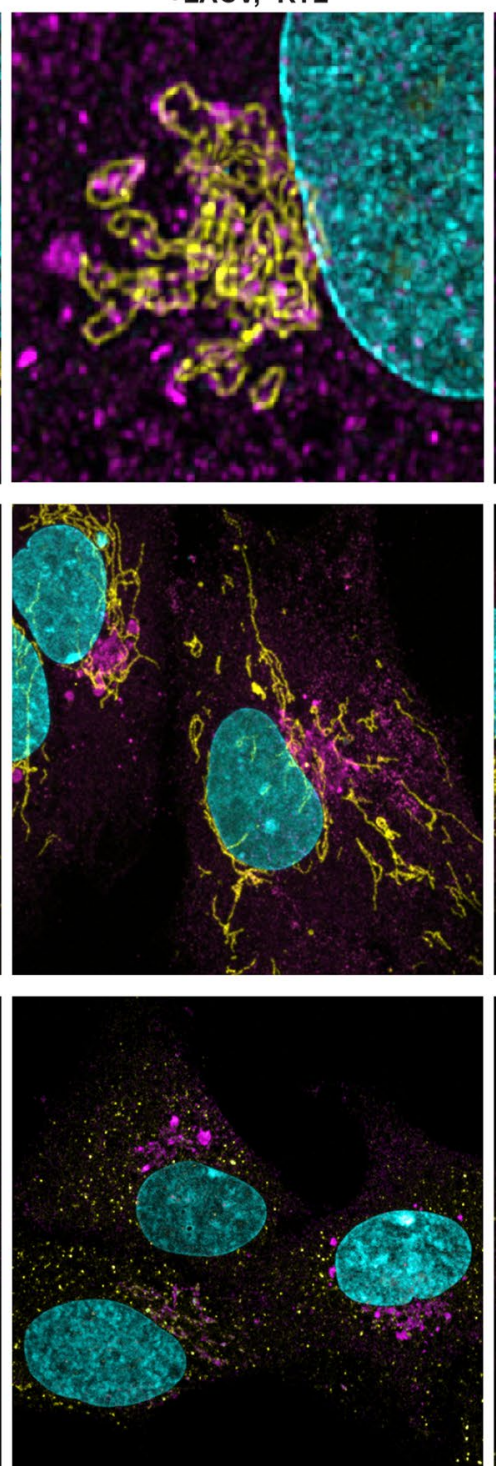

+LACV, +RTL
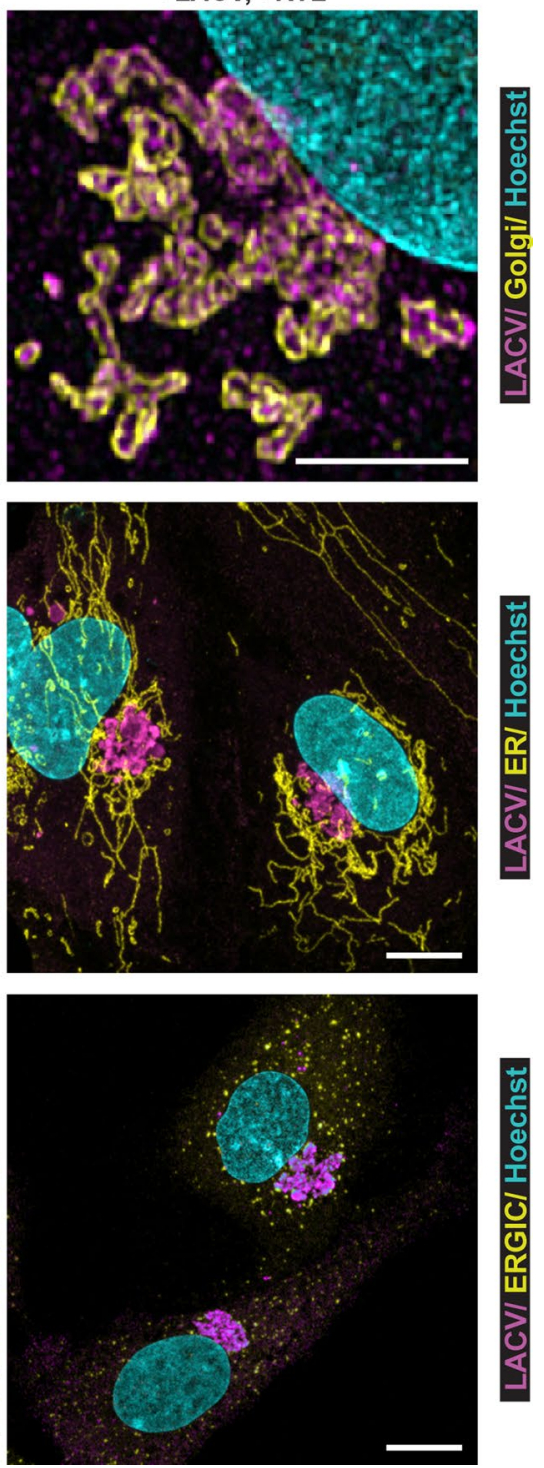

Extended Data Fig. 4 | See next page for caption. 
Extended Data Fig. 4 | (a) Effect of RTL or Brefeldin A separately or in combination on LACV RNA expression by qRT-PCR. To examine if RTL mediated virus inhibition through the same pathway as Brefeldin A, we analysed whether the two compounds had a synergistic or additive effect. hNSCs were cultured in 24-well plates ( $2 \times 10^{5}$ cells/well) and infected with LACV (MOI 0.1). At 1 hpi, cells were washed with PBS and fresh media containing different concentrations of Brefeldin A or RTL or both were added. At 24 hpi, cells were lysed, and RNA was collected for qRT-PCR analysis. Each data set represents the mean $\pm \mathrm{SD}$ of six replicate wells of two individual experiments. ${ }^{\star \star \star \star} \mathrm{P}<0.0001$; by one-way ANOVA using Dunnett's multiple comparisons test. (b-e) LACV co-localization with medial Golgi in hNSCs at different time intervals. hNSCs were grown in 8-chamber slide and infected with LACV. At different time intervals post-infection, infected cells were fixed with 4\% PFA and labelled using primary antibodies against LACV (magenta) and Giantin (yellow). (b) Cell control; (c) 6 hpi; (d) 8 hpi; (e) 12 hpi. Scale bar, $10 \mu \mathrm{m}$. Images are representative of 2 replicate experiments. (f) $2 X$ images from Fig. $2 b$ medial Golgi images. ( $g$ - $h$ ) Staining of $(g)$ ER and (h) ERGIC in LACV-infected, RTL-treated hNSCs. LACV infected hNSCs were treated with either DMSO or RTL at the dose of $2 \times \mathrm{EC}_{50}$ at $8 \mathrm{hpi}$. After $24 \mathrm{hpi}$, cells were immunostained with anti-LACV and either anti-Calnexin (ER) or anti-ERGIC antibody. Cells were imaged as described for Fig. 2. Scale bars (for all confocal images), $5 \mu \mathrm{m}$. Images are representative of 2-3 replicate experiments. 


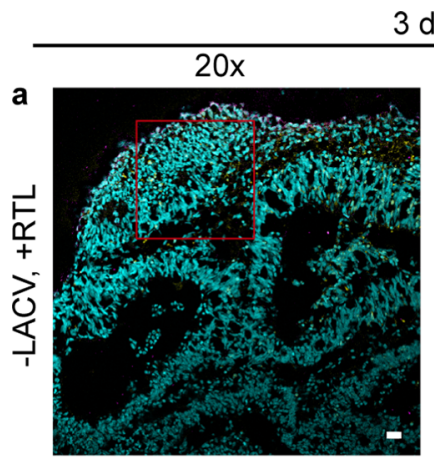

$3 \mathrm{dpi}$
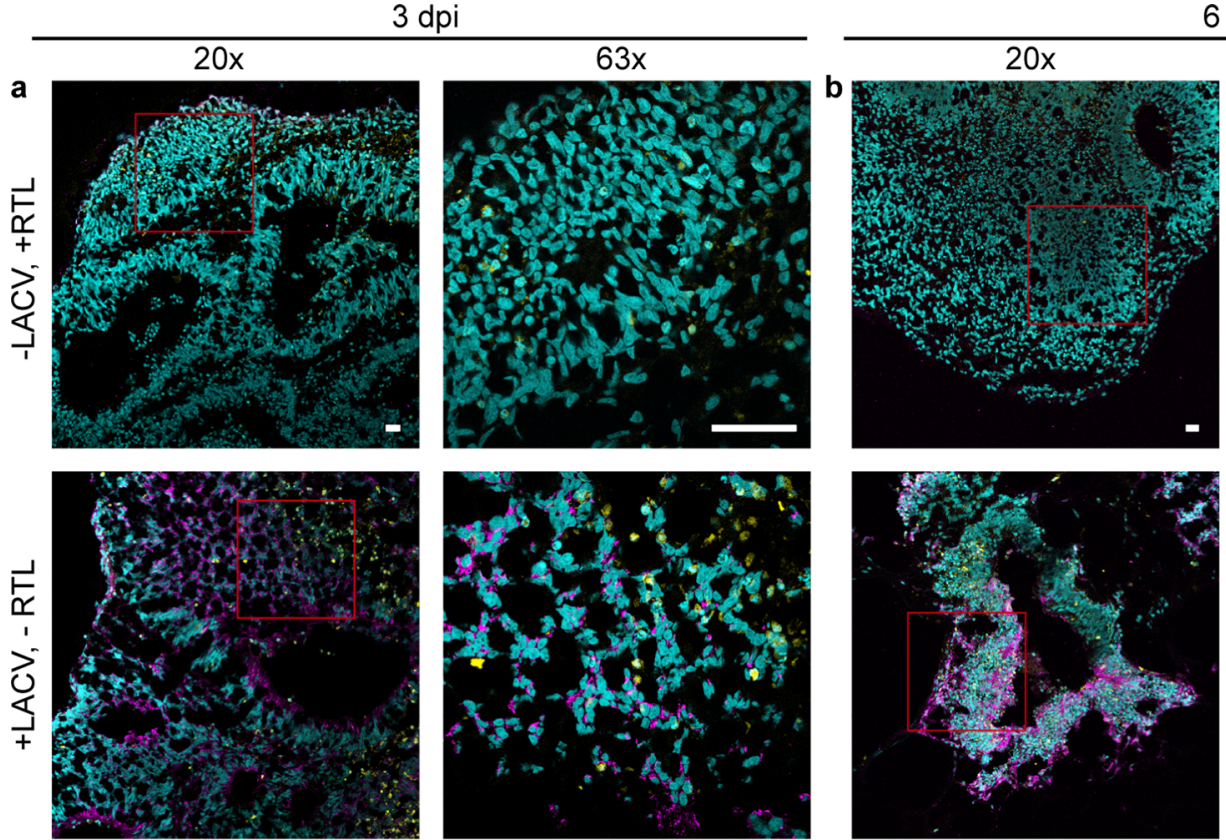

$6 \mathrm{dpi}$
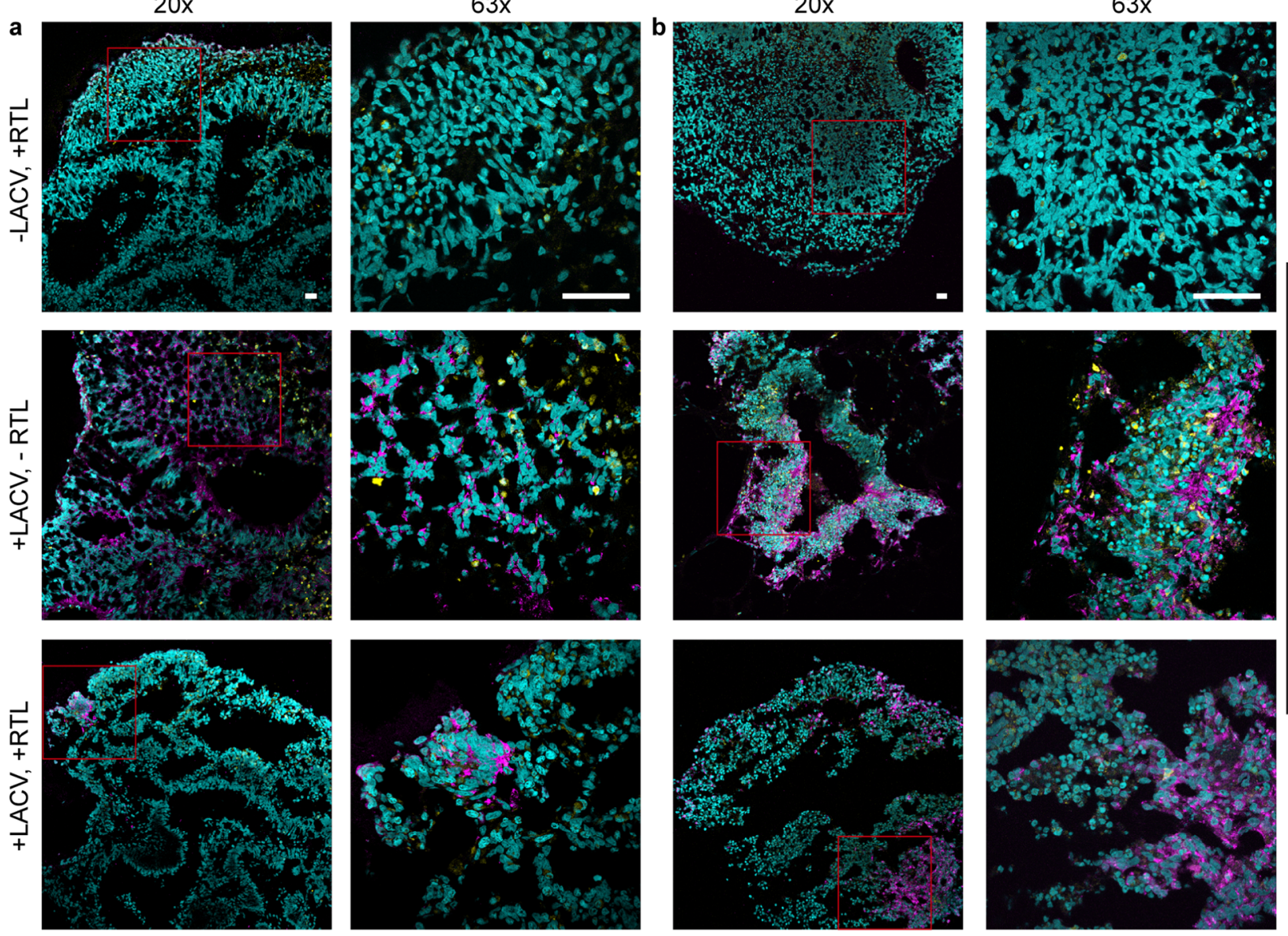

c

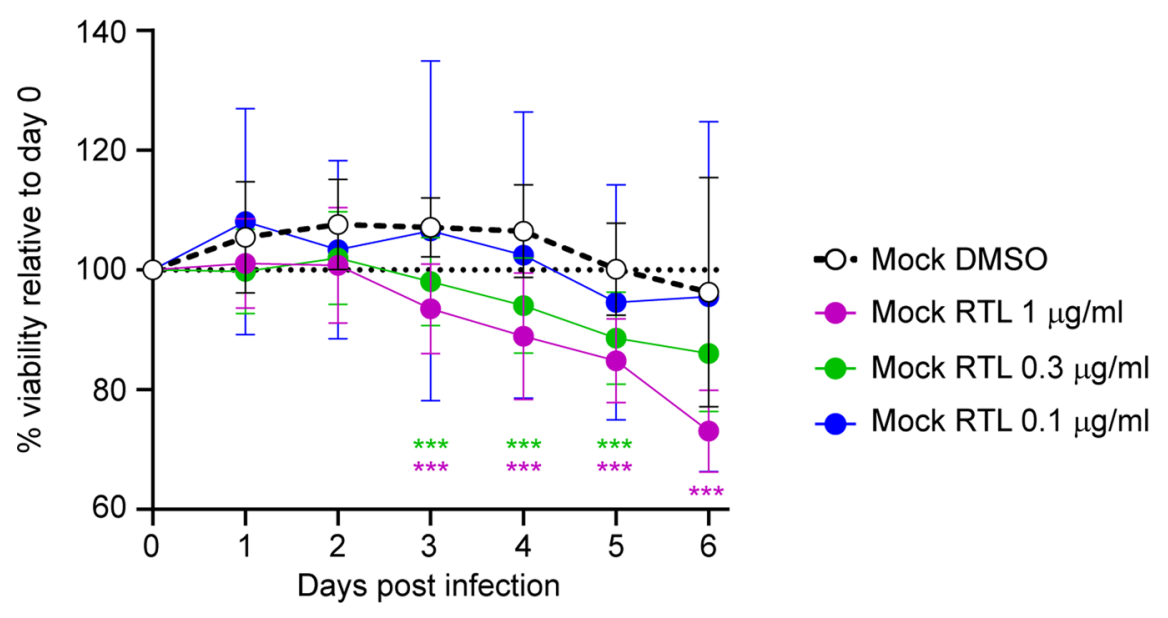

Extended Data Fig. 5 | Immunolabelling of LACV-infected hCOs treated with RTL. LACV-infected 3 week old hCOs were stained at (a) 3 dpi and (b) 6 dpi with LACV (magenta), Hoechst (cyan) and active caspase 3 (yellow). -LACV, +RTL indicates uninfected and RTL treated control; +LACV,-RTL (DMSO) indicates infection control treated with DMSO; $+\mathrm{LACV},+\mathrm{RTL}$ indicates infected and treated with RTL. Scale bars for all confocal images are $50 \mu \mathrm{m}$. Images are representative of 8-9 organoid per group. (c) Dose-dependent cell viability assay of RTL on 11 weeks old hCOs. Organoids were treated with 1, 0.3 and $0.1 \mu \mathrm{g} / \mathrm{ml}$ of RTL or DMSO up-to $6 \mathrm{dpi}$. Every day organoids were assayed for cell viability using a resazurin reduction-based colorimetric assay dye. Dye intensity was compared to the intensity on day 0 of the same organoid to calculate a percentage of viability compared to baseline. Each bar represents the mean $\pm \mathrm{SD}$ of an independent experiments of 6 organoids in each group. ${ }^{\star \star \star} \mathrm{P}<0.001$; by two-way ANOVA with a Dunnett's multiple comparisons tests. 

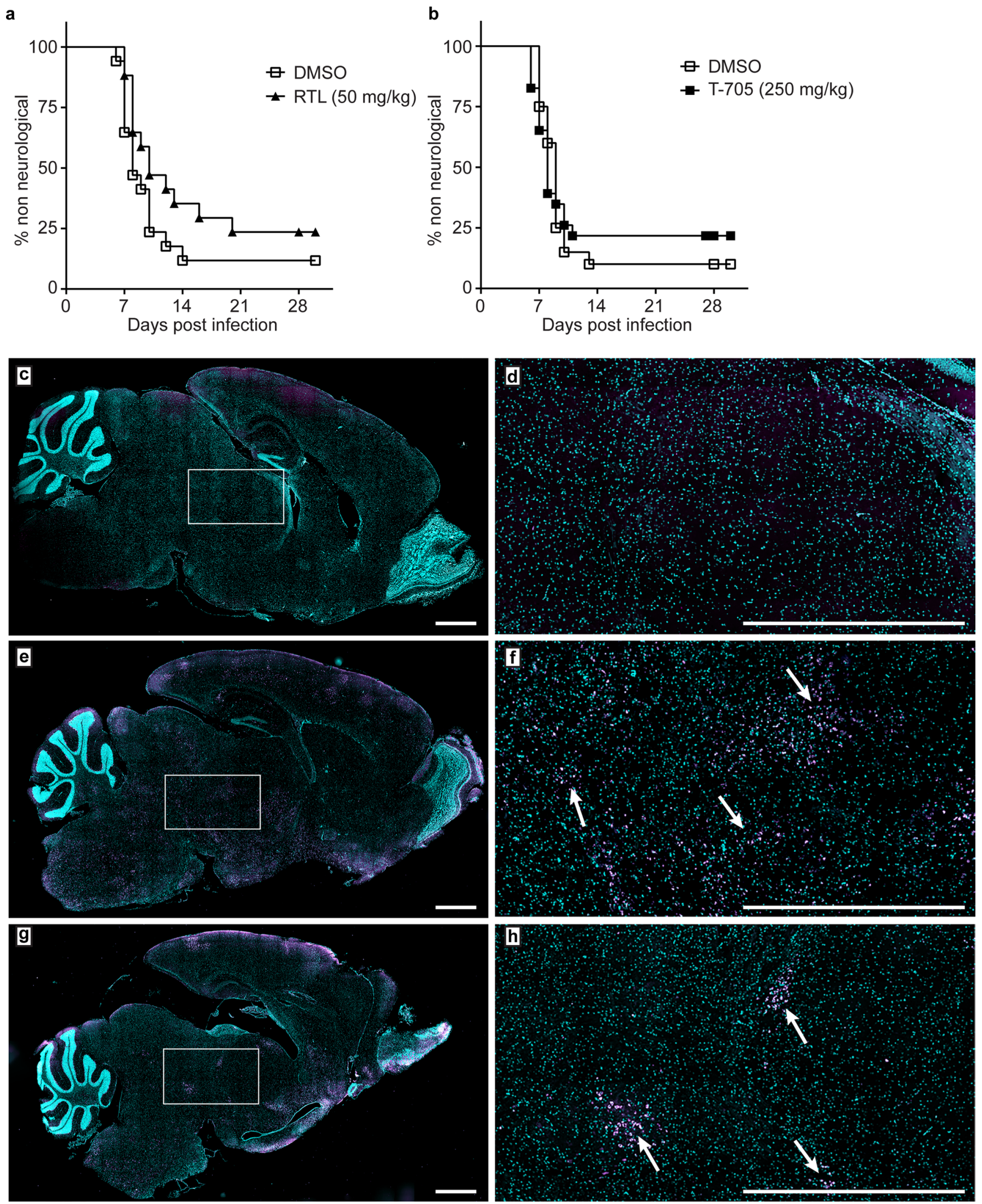

Extended Data Fig. 6 | See next page for caption. 
Extended Data Fig. 6 | In-vivo efficacy of (a) oral treatment of RTL or (b) IP treatment of FPV(T-705) on LACV-induced neurological disease. (a, b) A mix of male and female MAFIA mice at 22 to 24 days of age were infected with $1 \times 10^{3}$ PFU of LACV by intraperitoneal administration. (a) For oral treatment, mice were given RTL $(50 \mathrm{mg} / \mathrm{kg} ; \mathrm{n}=17)$ or DMSO $(n=17)$ daily for eight days starting at 3 dpi and then followed for signs of clinical disease. (b) For FPV IP treatment, mice were given FPV $(250 \mathrm{mg} / \mathrm{kg} ; \mathrm{n}=23)$ or DMSO $(n=20)$ daily for eight days starting at 3 dpi and then followed for signs of clinical disease. (c-h) Distribution of LACV antigen in brain sections of (c, d) uninfected RTL treated non-clinical mice and (e-h) LACV-infected (e, f) DMSO or $(\mathrm{g}, \mathbf{h})$ RTL IP-treated clinical mice. At $22-24$ days old mice were inoculated (IP route) with LACV ( $1 \times 10^{3}$ PUF/mice) or media (uninfected control). After $3 \mathrm{dpi}$, mice were treated IP either with RTL $(20 \mathrm{mg} / \mathrm{kg})$ or DMSO. Brains were removed from these mice at the initial appearance of clinical signs and processed for IHC. Virus is shown in magenta and nuclei are shown in cyan. $(d, f, h)$ are cropped images of caudate and thalamus region of (c, e, g) respectively. White arrows indicate the virus spread. Scale bar, $1 \mathrm{~mm}$. Images are representative of 2-4 mice per group. 

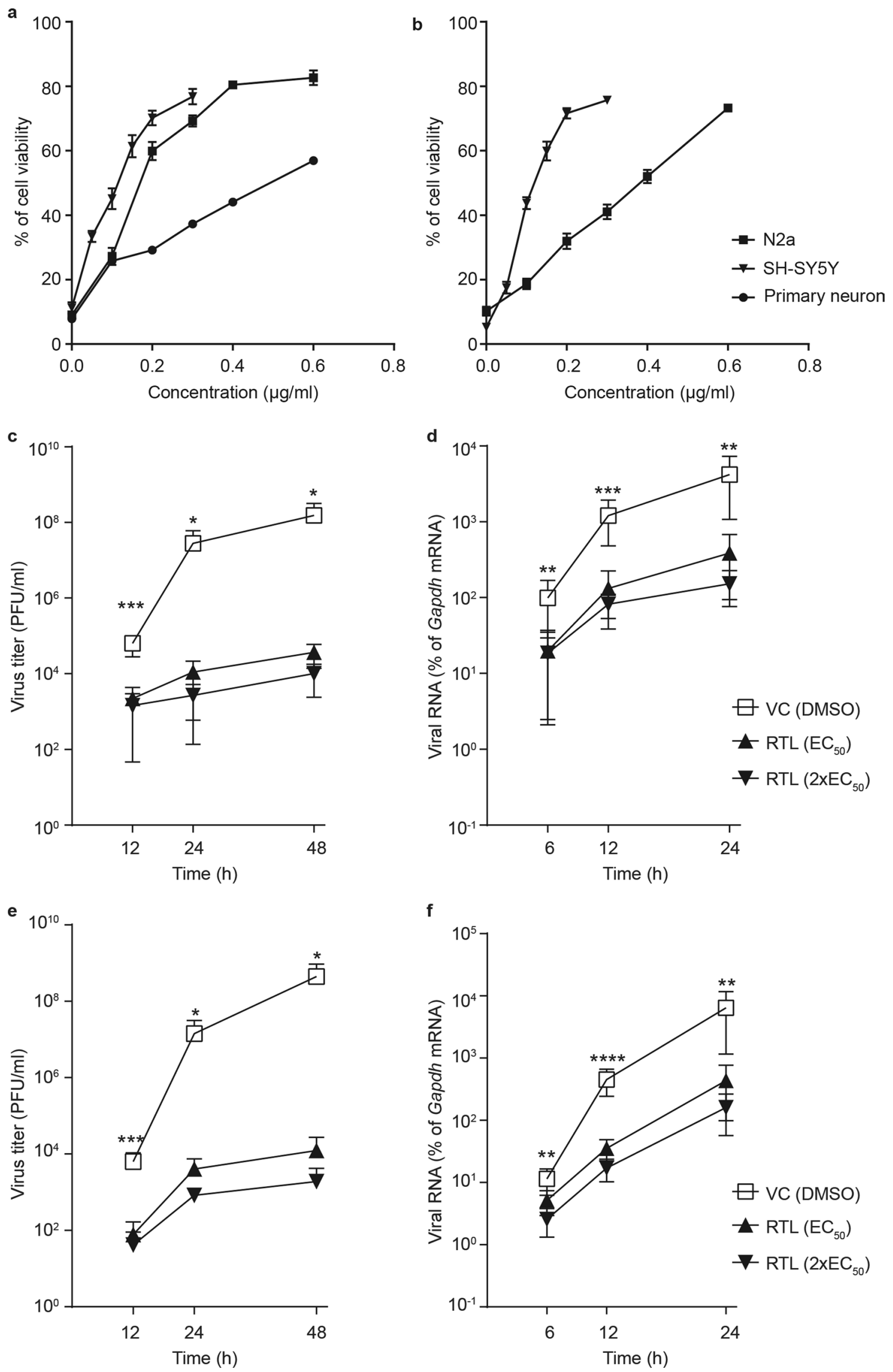

Extended Data Fig. 7 | See next page for caption. 
Extended Data Fig. $7 \mid(a, b)$ Dose-dependent activity of RTL on (a) JTCV and (b) TAHV-induced cell death. Cells (104 cells/well) were infected with either JTCV or TAHV (MOI 0.1). At $1 \mathrm{hpi}$, cells were treated with different concentrations of RTL or DMSO (0.1\%) as a control. At specific time intervals post infection (48 hpi for SH-SY5Y, or $72 \mathrm{hpi}$ for N2a and primary neurons), MTT assay was carried out and the percentage of cell viability was calculated as described in the methods. Each symbol represents the mean \pm SD of the combined data of triplicate wells from one to three independent experiments. (c-f) Effects of RTL addition on (c, d) JTCV and $(e, f)$ TAHV replication. SH-SY5Y cells ( $2 \times 10^{5}$ cells/ well of 24 well plate) were infected with (c, d) JTCV or $(e, f)$ TAHV (MOI 0.1) for 1 hour. Unbound virus was removed and RTL ( $E_{50}$ or $2 \times E_{50}$ ) or DMSO was added to appropriate wells. At indicated time points $(c, e)$ cell supernatant was harvested for plaque assay or $(d, f) R N A$ was isolated from cells for $q R T-P C R$. Each symbol represents the mean \pm SD of six individual wells combined from two independent experiments. ${ }^{\star} \mathrm{P}<0.05$; ${ }^{\star \star} \mathrm{P}<0.01$; ${ }^{\star \star \star} \mathrm{P}<0.001$ and ${ }^{\star \star \star \star} \mathrm{P}<0.0001$; by One-way ANOVA using Dunnett's multiple comparisons test. In $(d, f)$, the percentage viral RNA expression of cell control (CC; mock control) were between $10^{-1}$ to $10^{-3}$. 


\section{nature portfolio}

Corresponding author(s): Karin E. Peterson

Last updated by author(s): Aug 20, 2021

\section{Reporting Summary}

Nature Portfolio wishes to improve the reproducibility of the work that we publish. This form provides structure for consistency and transparency in reporting. For further information on Nature Portfolio policies, see our Editorial Policies and the Editorial Policy Checklist.

\section{Statistics}

For all statistical analyses, confirm that the following items are present in the figure legend, table legend, main text, or Methods section.

n/a Confirmed

$\square$ \.

$\square$ \ A statement on whether measurements were taken from distinct samples or whether the same sample was measured repeatedly

$\square$ The statistical test(s) used AND whether they are one- or two-sided

Only common tests should be described solely by name; describe more complex techniques in the Methods section.

Х $\square$ A description of all covariates tested

Х $\square$ A description of any assumptions or corrections, such as tests of normality and adjustment for multiple comparisons

$\checkmark$ A full description of the statistical parameters including central tendency (e.g. means) or other basic estimates (e.g. regression coefficient)

$\triangle$ AND variation (e.g. standard deviation) or associated estimates of uncertainty (e.g. confidence intervals)

$\varnothing$ For null hypothesis testing, the test statistic (e.g. $F, t, r$ ) with confidence intervals, effect sizes, degrees of freedom and $P$ value noted

Give $P$ values as exact values whenever suitable.

Х $\square$ For Bayesian analysis, information on the choice of priors and Markov chain Monte Carlo settings

Х $\square$ For hierarchical and complex designs, identification of the appropriate level for tests and full reporting of outcomes

$\bigotimes \square$ Estimates of effect sizes (e.g. Cohen's $d$, Pearson's $r$ ), indicating how they were calculated

Our web collection on statistics for biologists contains articles on many of the points above.

\section{Software and code}

Policy information about availability of computer code

Data collection Softwares and their version were used for data collection:

1. ViiA 7 Software 1.2 .2

2. ZEN v. 2.3 software

3. Gen5 v1.09.7 software

4. ZEN Blue 3.1 software

Data analysis Softwares and their version were used for data analysis:

1. GraphPad Prism v.7.04 and 8.20

2. Imaris x86_64 v. 9.5.1

3. Huygens Professional v 19.04

4. Microsoft Excel v. 2102

5. CMLE algorithm, with $\mathrm{SNR}=20$

For manuscripts utilizing custom algorithms or software that are central to the research but not yet described in published literature, software must be made available to editors and reviewers. We strongly encourage code deposition in a community repository (e.g. GitHub). See the Nature Portfolio guidelines for submitting code \& software for further information. 
Policy information about availability of data

All manuscripts must include a data availability statement. This statement should provide the following information, where applicable:

- Accession codes, unique identifiers, or web links for publicly available datasets

- A description of any restrictions on data availability

- For clinical datasets or third party data, please ensure that the statement adheres to our policy

The data that support the findings of this study are available from the corresponding author upon request. The primary screening data is made publicly available as PubChem bioassay assay ID (AID) 1508616 (Link: https://pubchem.ncbi.nlm.nih.gov/bioassay/1508616). Source data are provided in this paper.

\section{Field-specific reporting}

Please select the one below that is the best fit for your research. If you are not sure, read the appropriate sections before making your selection. $\bigotimes$ Life sciences $\quad \square$ Behavioural \& social sciences $\quad \square$ Ecological, evolutionary \& environmental sciences

For a reference copy of the document with all sections, see nature.com/documents/nr-reporting-summary-flat.pdf

\section{Life sciences study design}

All studies must disclose on these points even when the disclosure is negative.

$\begin{array}{lll}\text { Sample size } & \text { For all in vitro experiments, sample size was not calculated. However, based on previous experience with our cell culture system all }\end{array}$ experiments were set up with triplicate samples with three repeated experiments. This provides controls for both in-experiment variation and between-experiment variation.

For animal experiments

For Figure 6a: StatMate was used to calculate the number of animals to complete this study. With a predicted $80 \%$ of the mice developing clinical signs of disease, a sample size of 25 in infected group has an $80 \%$ power to detect a $30 \%$ decrease in survival proportion with a significance level (alpha) of 0.05 (two-tailed, Two Tailed analysis is necessary in case the results are opposite of what we expect.). For Figure 6b: StatMate was used to calculate the number of animals to complete this study. With a predicted $80 \%$ of the mice developing clinical signs of disease, a sample size of 9 in infected group has an $80 \%$ power to detect a $50 \%$ decrease in survival proportion with a significance level (alpha) of 0.05 (two-tailed, Two Tailed analysis is necessary in case the results are opposite of what we expect.).

Data exclusions A total of 12 mice were excluded from this study due to issues with either a mistake in virus dose or development of unrelated disease. One experiment was removed completely due to a mistake in the dose of virus inoculation (too low), which included 4 control mice and 5- RTLtreated mice (5) with no signs of disease in either group. One mouse was excluded due genital tract infection prior to infection and two mice (one DMSO and one FPV-treated) were removed due to hydrocephaly early on post-infection. This has been included in the methods section.

Replication All experimental groups are from 2-3 replicate experiments. Individual points from these experiments are combined and represented in the respective figures.

Randomization all in vitro experiments were completed using multi-well plates completed in triplicate. We did not complete specific randomization of these experiments as that can increase human error of highly complicated experiments with numerous wells. However, the nature of different sized experiments with different controls and different number of variables, the location of drug samples versus control samples are not in the same location of the plates, which does control for well location.

\begin{tabular}{l|l} 
Blinding & For immunohistochemistry, confocal, and EM samples, analysis were done in a blinded manner where the investigator did not know which
\end{tabular} samples were treated versus untreated. Mice studies were not blinded as the mice had to be treated with drugs during the time course when disease develops. However, the measurement of disease in this animal model is not subjective. Any clinical signs of neurological disease (ataxia, seizures or paralysis) results in a score of clinical. Additionally, disease progresses very fast in these animals as a mouse showing mild signs of disease will progress to severe signs of disease or death within $1 / 2$ a day. In terms of MTT assays, qRT-PCR and PFU assay, the number of samples and the method of collection/analysis does not allow determination by the investigator as to which samples are controls versus treated. We did conduct the organoid analysis in a blinded analysis where the investigator analyzing the data did not know which sample was which until after the experiment was completed.

\section{Reporting for specific materials, systems and methods}

We require information from authors about some types of materials, experimental systems and methods used in many studies. Here, indicate whether each material, system or method listed is relevant to your study. If you are not sure if a list item applies to your research, read the appropriate section before selecting a response. 
Materials \& experimental systems

\begin{tabular}{l|l}
\hline$n / a$ & Involved in the study \\
\hline & $\bigotimes$ Antibodies \\
$\square$ & $\bigotimes$ Eukaryotic cell lines \\
$\square$ & $\square$ Palaeontology and archaeology \\
$\square$ & $\square$ Animals and other organisms \\
$\square$ & $\square$ Clinical data
\end{tabular}

Methods

\begin{tabular}{l|l}
\hline n/a & Involved in the study \\
$\square$ & $\square$ ChIP-seq \\
$\square$ & $\square$ Flow cytometry \\
$\square$ & $\square$ MRI-based neuroimaging
\end{tabular}

\section{Antibodies}

Antibodies used

\section{Antibody Name}

1. Mouse Anti-LACV polyclonal antibody

2. Rabbit Anti-LACV polyclonal antibody

3. Purified Mouse Anti-GM130

Clone 35/GM130

4. Rabbit Anti-Giantin Antibody

5. Rabbit Anti-TGN46 Antibody

6. Rabbit Anti-ACTIVE ${ }^{\circledR}$ Caspase-3

7. Rabbit antiERGIC-53/p58 antibody

8. Mouse Calnexin Monoclonal antibody (AF18)

9. Rabbit Recombinant Anti-NeuN antibody

10. Mouse Anti-MAP2 antibody, clone AP20

11. Goat Anti-GFP antibody

12. Goat anti-Mouse IgG $(H+L)$ Secondary Antibody, Alexa Fluor 488

13. Donkey anti-Mouse $\lg G(\mathrm{H}+\mathrm{L})$ Secondary Antibody, Alexa Fluor 594

14. Goat anti-Rabbit IgG $(\mathrm{H}+\mathrm{L})$ Secondary Antibody, Alexa Fluor 594

15. Chicken anti-Rabbit IgG $(\mathrm{H}+\mathrm{L})$ Secondary Antibody, Alexa Fluor 488

16. Donkey anti-Rabbit IgG $(\mathrm{H}+\mathrm{L})$ Highly Cross-Adsorbed Secondary Antibody,

17. Donkey anti-Goat IgG $(\mathrm{H}+\mathrm{L})$ Secondary Antibody, Alexa Fluor 488
Supplier name

In-house generated hyperimmune serum In-house generated hyperimmune serum BD Bioscience, USA

BioLegend, USA

Sigma-Aldrich, USA

Promega, USA

Sigma-Aldrich, USA

ThermoFisher Scientific, USA

Abcam, MA, USA

MilliporeSigma, MA, USA

Abcam, MA, USA

ThermoFisher Scientific, USA

ThermoFisher Scientific, USA

ThermoFisher Scientific, USA

ThermoFisher Scientific, USA

ThermoFisher Scientific, USA

594

ThermoFisher Scientific, USA
Catalog number/Lot number

$610822 / 8004852$

924302/B264559

ABT95/2983243

G748A/0000155356

E1031/125M4888V

MA3-027/TC262423

ab177487/GR249899-17

ab6673/GR270465-2

A11001/1890503A

A21203/1608644

A11037/1588554

A21441/737677

A21207/2066086

A11055/1627966

Validation

All secondary antibodies were tested using a no-primary control on the tissues being analyzed. Validation of golgi markers were confirmed by specific localization in control cells as well as confirming disruption of this staining in Brefeldin A treated cells (which disrupts the golgi in these cells). Rabbit anti-ACTIVE Caspase 3 antibody was validated by lack of staining in uninfected human and mouse cell lines. Additionally, we have previously published ACTIVE Caspase 3 staining in human Cerebral organoids showing significant increase with immunohistochemistry (Fig. 3B vs 3C in Winkler et al, J. Neuroinflammation, 2019) That data also matched our flow cytometry analysis of organoids for active-caspase 3 positive cells as well.

For LACV-specific antibodies, all experiments were done with a uninfected control as well as a non-primary control to ensure no staining in those controls. Those samples were negative for all of our experiments (as shown in Extended Data 6c,d). Primary antibody against specific organelles were utilized based on previous experience with those antibodies and were confirmed by expected localization to the correct organelle and previous experiments with similar localization.

\section{Eukaryotic cell lines}

Policy information about cell lines

Cell line source(s)

1. SH-SY5Y ATCC ${ }^{\circledR}$ CRL-2266 ${ }^{\text {TM }}$

2. H9 human embryonic stem cell Thermo Fisher Scientific -Invitrogen

derived human neural stem cells (hNSCs) (Catalog nos. N7800-100)

3. Neuro-2a (N2a) ATCC ${ }^{\circledast}$ CCL-131

4. C17.2 Sigma-Aldrich, USA (07062902-1VL)

5. Vero cells ATCC ${ }^{\oplus}$ CRL-1587

Authentication

Neuronal cells were stained for neuronal and neuronal progenitor markers to confirm the expression of neuronal lineage markers. The only cell line that was not a neuronal cell was the Vero cells. We did not authenticate the Vero cell line.

These cell lines were not tested for mycoplasma contamination for these studies. 
Commonly misidentified lines (See ICLAC register) no commonly misidentified cell lines were used in this study

\section{Animals and other organisms}

Policy information about studies involving animals; ARRIVE guidelines recommended for reporting animal research $\begin{array}{ll}\text { Laboratory animals } & \text { 22-23 days old, mixed sex, Macrophage Fas-Induced Apoptosis (MAFIA) mice (C57BL/6-Tg(Csf1r-EGFP-NGFR/FKBP1A/ } \\ \text { TNFRSF6)2Bck/J Stock No: 005070) were used for this study }\end{array}$

Wild animals no wild animals were used in this study

Field-collected samples no field-collected samples were used in this study

Ethics oversight

Protocol 2016-016-E and 2019-23 which were approved by the NIH/NIAID/RML Institutional Animal Care and Use Committee Note that full information on the approval of the study protocol must also be provided in the manuscript. 